\title{
Quantifying Isolation-by-Resistance and Connectivity in Dendritic Ecological
}

\section{Networks}

Tyler K. Chafin ${ }^{1,2}$, Steven M. Mussmann ${ }^{1,3}$, Marlis R. Douglas ${ }^{1}$, and Michael E. Douglas ${ }^{1}$

${ }^{1}$ Department of Biological Sciences, University of Arkansas, Fayetteville, AR 72701

${ }^{2}$ Department of Ecology and Evolutionary Biology, University of Colorado, Boulder, CO 80309

${ }^{3}$ Southwestern Native Aquatic Resources and Recovery Center, U.S. Fish \& Wildlife Service, PO

Box 219, Dexter, NM 88230

Corresponding author and person to whom reprint requests should be addressed:

Tyler K. Chafin

Department of Ecology and Evolutionary Biology

University of Colorado

Boulder, CO 80309

e-mail: tyler.chafin@colorado.edu

Keywords: Gene flow; isolation-by-distance; stream hierarchy; riverscape genetics; landscape resistance 
2 Statistical methods that quantify individual movements have limited applicability within dendritic ecological networks (DENs), to include riverscapes. We promote an approach herein by

4 deriving an analytical framework (=DISTNET and RESISTNET) that more appropriately quantifies differentiation by meshing individual DEN segments with fitted distances and annotated

6 environmental features. We first explored the spatial arrangement of diversity in a river network by fitting pairwise distances against graph edges. We then derived effective resistance models

8 (e.g., as a composite of an array of possible environmental covariates) by using a genetic algorithm for heuristic model selection, invoking circuit theory (CIRCUITSCAPE) to form a graph-

10 based complement to RESISTANCEGA (a landscape ecology package). Although numerous pairwise distance metrics can be employed, we utilized genetic distances encompassing 13,218

12 ddRAD loci from $N=762$ Speckled Dace (Cyprinidae: Rhinichthys osculus) sampled at 78 Colorado River localities $(\mu=9.77 /$ site $)$. When distances for each locus were fitted into the

14 network, we found intraspecific divergences due to stream reaches were greater than expected when distances alone. In fitting model-averaged 'effective resistance' models to the same

16 network, we showed the manner by which a host of anthropogenic and environmental variables contribute to patterns of connectivity underlying riverscape genetic differentiation. Our

18 framework represents a contemporary approach to deriving metapopulation/metacommunity structure within DENs, in that it allows: (a) The extension of projections into unsampled

20 temporal/spatial components; (b) Comparisons to be made among species and/or drainages, both of which benefit multi-species management; and (c) the quantification of locus-specific patterns,

22 from which adaptive hypotheses could then be derived. 
24 "The intimate relation of hydrological conditions to fish life is proverbial; to be hopelessly or

25 dangerously maladjusted to one's environment is to be a 'fish out of water"' (Hubbs 1941).

27 1. INTRODUCTION(1352)

28 The physical structure of watersheds not only defines the form and function of freshwater fishes

29 (Douglas and Matthews 1992, Jackson et al. 2001), but also their intraspecific evolutionary

30 trajectories and population dynamics (Mussmann et al. 2020b). Despite similar approaches, the

31 resulting patterns of diversification differ markedly from those found in terrestrial landscapes

32 and 'seascapes' (Martinez et al. 2018, Manel et al. 2020, Rabosky 2020). This is because the

33 unique constraints found in riverine networks not only serve to define dispersal pathways but

34 also as a template that dictates genetic relatedness within/ among aquatic biota (Meffe and

35 Vrijenhoek 1988). Network 'connectivity' (=potential for movement) and ‘complexity'

36 (=branching rates/ nonlinear topology) thus represent constraints that control numerous

37 population processes, such as: Genetic divergence (Hopken et al. 2013), colonization

38 probabilities (Labonne et al. 2008, Falke et al. 2012), and ephemerality of metapopulation

39 components (Fagan 2002, Campbell Grant 2011).

In general, complex dendritic networks may promote intraspecific genetic diversities

41 (Thomaz et al. 2016), and divergences among distal (e.g., headwater) populations (Chiu et al.

42 2020a). Yet, the unidirectional flows in riverscapes differ from other such dendritic ecological

43 networks (DENs), and thus acts to bias the patterns of dispersal found therein (i.e., up- versus

44 downstream). This in turn promotes asymmetric gene flow and a source-sink metapopulation

45 structure (Campbell Grant et al. 2007). Consequently, a prevailing trend is for a downstream

46 increase in allelic diversity (Paz-Vinas and Blanchet 2015, Paz-Vinas et al. 2015, Blanchet et al. 
47 2020), whereas unique genetic variation is most often retained within more peripheral headwater populations (Morrissey and De Kerckhove 2009, Chiu et al. 2020b). and Fronhofer 2018, Shen et al. 2018) and reduced genetic variability (Thomaz et al. 2016)

51 within unimpeded linear systems that, in turn, impacts both resilience and stability of lineages

52 (Mari et al. 2014, Seymour et al. 2015, Terui et al. 2019), as well as their capacity to proliferate

53 (Harvey et al. 2019). However, numerous labile conditions can also serve to alter these

54 expectations, such as: Life histories [e.g., directionality of dispersal bias (Chiu et al. 2020a)],

55 nonequilibrium population processes (Pilger et al. 2017), geomorphic and climatic regimes

56 (Douglas et al. 1999, Osborne et al. 2014), and abiotic species-level interactions (Paz-Vinas et al.

57 2015, Rodríguez-González et al. 2019).

It is thus not surprising that a singular evaluation of stream distances rarely captures

59 intraspecific genetic patterns. For example, in a comparison of 12 salmonid species, the $R^{2}$-value

60 for isolation-by-distance (IBD) varied from $0.06-0.87(\mu=0.51 ; \sigma=0.26$; Bradbury and Bentzen

61 2007), and from 0.0001-0.44 among three species of darter (Camak and Piller 2018). Although

62 such deviations are partly driven by stochastic or nonequilibrium processes (Hutchison and

63 Templeton 1999), their residuals should also reflect those spatial features that impede individual

64 movements (Keis et al. 2013, Tang et al. 2020). Thus, divergence can alternatively be considered

65 as a function of the movement-cost along stream segments, i.e., 'isolation-by-resistance' (IBR:

66 McRae, 2006; McRae \& Beier, 2007).

67 The IBR model applied within dendritic networks emphasizes specific attributes of

68 individual edges or stream segments, and an array of localized factors have been identified as

69 contributing to resistance (Hughes et al. 2009, Fullerton et al. 2010). These include: Rate of 
70 elevational change (Lowe et al. 2006), flow regime (Rolls et al. 2016), channel width/ catchment

71 area (Ma et al. 2020), water composition (Fourtune et al. 2016), and seasonal hydroclimatic

72 fluctuations (Brauer et al. 2016, 2018). In addition, organisms that never (or but rarely) occupy

73 upstream or headwater conditions can still be directly affected by those habitats (Frissell et al.

74 1986, Nadeau and Rains 2007, Fullerton et al. 2010).

Most linear streams are also inherently predisposed to fragmentation (Fagan 2002, Fagan

et al. 2002, Brauer and Beheregaray 2020), a situation particularly exacerbated in the

77 Anthropocene such that relatively few now remain 'free-flowing' (Grill et al. 2019). Water

78 storage also impacts habitat suitability (Chafin et al. 2019, Fraser et al. 2019), and also shifts

79 population trajectories (Dibble et al. 2020). Dams and diversions either extirpate populations

80 (Brauer and Beheregaray 2020), or disrupt homing behaviors so as to promote homogenization

81 (Baggio et al. 2018), with species of limited mobility particularly impacted (Coleman et al.

82 2018). Again, vulnerability and the specific nature of impacts vary by context and species

83 (Prunier et al. 2018).

\section{1 | Applying landscape genetic methods to riverscapes}

The mechanics of landscape genetics/genomics often translate poorly to dendritic

87 networks, and this in turn creates a disparity with regard to the number of 'riverscapes' analyzed

88 (Davis et al. 2018, Grummer et al. 2019). At issue is the explicit consideration of riverscape

89 structure upon which genetic relationships can be mapped. Frequent ad hoc approaches often

90 employ (a) methods that lack a spatial framework (such as STRUCTURE; Pritchard et al. 2000), or

91 (b) procedures commonly applied in landscape genetics, such as matrix dissimilarities (e.g.,

92 Kanno, Vokoun, \& Letcher, 2011; Cooke, Landguth, \& Beheregaray, 2014; Galbraith, Zanatta, 
$93 \&$ Wilson, 2015). The latter, while capable of testing spatio-genetic associations, does so by

94 contrasting a genetic distance matrix against pairwise differences in local conditions (e.g.,

95 Mantel test and derivatives; Douglas and Endler, 1982; Smouse, Long, \& Sokal, 1986). These

96 are controversial methods, in that the space separating sampling points is generally not evaluated

97 (Legendre and Fortin 2010; Legendre et al. 2015; Peterman and Pope 2020). For riverscapes, this

98 equates to those attributes of stream segments through which migrants must travel (Davis et al.

99 2018).

100

On the other hand, path-based methods consider the cumulative costs of movement

101 among points, under the premise that multi- or omni-directional movements are available (an

102 assumption that may not apply within riverscapes). Those environmental features encountered

103 during movements are subsequently converted into 'resistance values' (Zeller et al. 2012), with

104 the resulting 'surface' allowing for habitat-related metrics to be derived, such as: Least-cost

105 paths, net flux between points, and movement corridors (Shah and McRae 2008, McRae et al.

106 2016). Operationally, this involves summarizing spatial variables as a raster image of $n \times m$ cells

107 (analogous to pixels), with numerical resistance values assigned so as to form an 'effective

108 resistance network' (Davis et al., 2018). Here, riverscapes transition into a graph structure, with

109 nodes (i.e., populations or junctions) connected by edges annotated with environmental attributes

110 (Eros et al. 2011, Peterson et al. 2013).

111 Few approaches have considered resistance within a spatially explicit graph-theoretic

112 framework, and even fewer have done so by involving multiple covariates in an hypothesis-

113 testing framework [although see White, Hanks, \& Wagner (2020)]. Here, it becomes necessary

114 to employ an heuristic approach that explores complex parameter space, particularly given the

115 sensitivity of resistance models to parameterization and the difficulties with the a priori 
116 weighting of specific variables within a larger pool of candidates (Spear et al. 2010). Such

117 approaches have been developed for landscapes, using model exploration and selection

118 algorithms (RESISTANCEGA: Peterman, 2018) successful in both empirical and in silico

119 scenarios (Peterman et al. 2019, Kimmig et al. 2020, Winiarski et al. 2020).

120 Here, we employ resistance model perspectives as a mechanism to quantify riverscape

121 genetics/genomics, and do so by exploiting recently developed, large-scale efforts that quantify/

122 classify stream variables (McManamay et al. 2018, Grill et al. 2019, Linke et al. 2019, Troia and

123 McManamay 2020). Our approach modifies those methods that fit distances to network edges

124 with others that subsequently optimize graph-based resistance models (Kalinowski et al. 2008).

125 We utilized our package to evaluate a case study involving Speckled Dace (SPD;

126 Cyprinidae, Rhinichthys osculus), the most widely-distributed species within the most

127 endangered and regulated river system of North America, the Colorado River (Minckley and

128 Deacon 1968, Nilsson et al. 2005, Grill et al. 2019). To accomplish this, we analyzed a large

129 ddRAD dataset as a means to test the following hypotheses: 1) SPD populations are structured

130 according to contemporary riverine connectivity; 2) Their genetic diversity is driven by the

131 topology of the dendritic network; 3) Genetic differentiation is modulated by environmental

132 attributes, represented as edges within the river network; and 4) Spatio-genetic patterns are not

133 explained by distance alone but rather by an isolation-by-resistance model.

135 2. METHODS (3098)

2.1 | The automation of population genetic analyses in dendritic networks

137 Two complementary software tools, DiSTNET and RESISTNET, facilitate high-throughput

138 analyses by employing two complementary software tools that automate the exploration of 
139 environmental correlates as well as the analyses of genetic differentiation in dendritic networks

140 (i.e., DistNet, RESISTNET; Fig. 1). Both are available as open-source which also includes

141 instructions for virtual deployment as well as installation from scratch

142 (github.com/tkchafin/DENdriscape).

\subsection{1 | The fitting of edge-wise genetic distances}

145 The DisTNET workflow (Fig. 1) parses geospatial input files (as .shp) representing large stream 146 networks in which streams=edges, and endpoints or junctions=nodes. It does so by: 1) 'snapping'

147 sample points to nodes in the river network; 2) Identifying shortest paths between each set of

148 points using Dijkstra's algorithm (Dijkstra 1959), (as implemented in NETWORKX; Hagberg et al.

149 2008); and 3) Constructing a minimized network representation, preserving original geometries,

150 forming contiguous edges by joining individual stream reaches/ segments, and retaining only

151 those junctions necessary to fulfil shortest Dijkstra paths between points. DISTNET will annotate

152 final results as part of the original geospatial dataset. Given this, we recommend employing the

153 RIVERATLAS dataset (hydrosheds.org/page/hydroatlas) that contains pre-calculated variables

154 representing various aspects of local-scale hydrology (such as physiography, climate, land-cover,

155 geology, and anthropogenic effects) (Linke et al. 2019). This not only simplifies downstream

156 analysis (as herein) but also facilitates visualization of results using graphical geospatial software

157 such as ARCGIS (Esri, Inc.) or QGIS (www.qgis.org).

158 DISTNET will then calculate pairwise measures of genetic differentiation and stream

159 distances among individuals, sites, or populations. For individual-based metrics, we implemented

160 both uncorrected $p$-distances (i.e., proportion of nucleotide differences over the alignment

161 length), as well as corrected measures [e.g., TN93 (Tamura and Nei 1993)]. Several frequency- 
162 based metrics can also be implemented for population- or site-wise calculations, as well as

163 whole-locus single alignments, multi-locus alignments, or SNP datasets. These are: $\theta_{\mathrm{ST}}$ (Weir

164 and Cockerham 1984); G' ${ }_{\text {Sт }}$ (Hedrick 2005); $G{ }^{\prime}{ }_{\text {Sт }}$ (Meirmans and Hedrick 2011); Linearized

$165 \quad F_{\text {ST }}$ (Rousset 1997); Jost's $D$ (Jost 2008); Chord distance (Cavalli-Sforza and Edwards 1967), as

166 well as others (github.com/tkchafin/DENdriscape). For more efficient computation when very

167 large numbers of SNPs are employed (as herein), we also recommend that locus-wise distances

168 be pre-calculating using ADEGENET (Jombart 2008) Scripts again available at:

169 github.com/tkchafin/DENdriscape/scripts.

Although isolation-by-stream-distance methods are available in DISTNET, the primary

171 approach is the Kalinowski et al. (2008) model in which a least-squares optimization procedure

172 (Felsenstein 2004) is utilized to fit branch lengths. Here, the procedure begins with a matrix of

173 pairwise genetic distances, then seeks to map those stream distances as explained by $k$ segments

174 in a network, such that the fitted distance values $(r)$ for each segment separating two populations

175 will sum to the observed value from the pairwise matrix. The result is a distance $\left(r_{k}\right)$ for each of $k$

176 segments that represents the genetic distance 'explained' by that segment (Fig. 1; see also

177 Kalinowski et al. 2008).

178 The underlying mathematical implementations include an iterative, constrained

179 optimization approach that corrects for negative-fitted distances (per Kalinowski et al., 2008).

180 However, we provide an additional opportunity for alternative weighting within the least-squares

181 optimization (e.g., Fitch \& Margoliash, 1967), that will alter the weight of distances based upon

182 their similarity, which may in turn be beneficial when rates of change vary among branches (or

183 in this case, stream edges; Felsenstein 2004). In addition, the original method (Cavalli-Sforza

184 and Piazza 1975) also remains available for subsequent implementation. 
Fitted distances can either be computed either for a single locus, as an aggregate (e.g., arithmetic mean) across loci. The result is a table of fitted distances per stream segment (and per-

187 locus, if so requested), as well as an annotated version of the original geospatial data. Each can

188 be employed for downstream analysis, as demonstrated in our case study. Interestingly, DISTNET

189 can be re-calculated using graphs previously constructed as input (i.e., as a programmatic

190 option).

\subsection{2 | Composite resistance models optimized within networks}

193 RESISTNET combines a genetic algorithm with multiple environmental variables so as to explore

194 the parameterization of resistance models (Fig. 1), similar to a process found in RESISTANCEGA

195 (Peterman 2018), but with several important differences. For example, genetic algorithms are

196 useful in modelling optimization and selection of features in that they are less impacted by local

197 optima when compared to other 'hill climbing' techniques (Prügel-Bennett 2004). They are

198 employed to simultaneously evaluate a 'population' of models by using log-likelihood or AIC to

199 gauge 'fitness.' Here, 'individuals' (as randomly sampled model configurations) consist of

200 'chromosomes,' with 'genes' (as parameter choices) being represented by: 1) Variable

201 inclusion/exclusion; 2) Variable transformations (using transformation functions available in

202 RESISTANCEGA; Fig. S1); 3) Shape parameters for transformation; or 4) Variable weights (with 203 user-defined ranges).

204 For an optimization problem involving $n$-environmental parameters, an individual 205 chromosome is represented as length $=4 n$. Fitness values (e.g., AIC) then determine the survival

206 of individual models and their contribution to successive generations, with stochasticity

207 represented by mutation (random changes to parameter values) and recombination (parameter 
208 choices from multiple individuals combined as offspring). Optimization continues until a

209 threshold number of generations have passed without the fitness of the population increasing

210 (Scrucca, 2013).

211 The optimization process is summarized as follows (with the DEAP evolutionary

212 algorithm package enabling implementation; Fortin et al. 2012):

213 1. Network structure and environmental data are imported, using the output formats of

214 DisTNET. Environmental data for contiguous stream reaches (=edges) are summarized

215 and rescaled from 0-10, following Peterman (2018).

2162 . The initial population is randomly seeded, with a user-defined population size.

217 Individuals are composed chromosomes of length $n^{*} 4$, where $n=$ the number of

218 environmental variables (as above). Transformation, shape, and weight parameters ensure

219 that an optimal scale can be 'found' with respect to a potential non-linear relationship

220 between gene flow and each variable, while also allowing the latter to vary in a

221 composite resistance modelwith regards to relative influence and direction (e.g., positive

$222 \quad$ or negative).

223 3. Individual fitness is calculated using a custom function, wherein all selected variables are

224 transformed according to the chosen parameters, then re-scaled and combined using a

225 weighted additive function to form a single composite set of resistance values that

226 annotate the original network. Cumulative effective resistance between nodes is then

227 computed using CIRCUITSCAPE. Final calculations employ a maximum likelihood

228 population effects (MLPE) linear mixed effects model to compare pairwise genetic

229 distances with scaled and centered resistance distances, fitted using the MLPE function

230 from RESISTANCEGA (via the RPY2 interface; Gautier 2008). Fitness is then returned via 
options available in RESISTANCEGA as either log-likelihood, AIC, or marginal $R^{2}$. Fitness can also be computed using $\triangle \mathrm{AIC}_{\text {null, }}$, or the change in $\mathrm{AIC}$ values via the MLPE-fitted model, as compared to a 'null' model composed of only random effects.

4. Individuals are 'selected' for successive generations using a tournament selection scheme, a deterministic method whereby random sets of individuals of size $n$ specified by the user are compared (=tournaments), with 'winners' being retained.

5. Mutation (=changing parameter values) and recombination (=exchanging parameter combinations among models) occur at generational intervals, with the respective probabilities of both processes as user-specified.

6. Steps 2-5 are repeated for a user-specified number of generations, or until a number of user-specified generations fail to increase the maximum fitness beyond a given threshold. observed in the population, with models retained so as to meet a cumulative userspecified Akaike weight threshold (default value=0.95). Model-averaged resistance and multi-model, relative variable importance values are subsequently computed using the chosen model set (below). selection, in that the estimates from every candidate model are integrated proportional to their

250 approximation of the observed genetic distances (using the Akaike weight; $w_{\mathrm{i}}$ for $i$ models),

251 while also more concisely incorporating both uncertainty and information from closely-ranked

252 models. Additionally, it also allows relative variable importance (RVI) to be quantified across

253 models composed of different numbers of explanatory variables, and does so by deriving the sum 
254 of Akaike weights that correlate well with in silico evaluations of $r^{2}$ variable rankings (Giam and

255 Olden 2016).

256

2572.2 Rhinichthys osculus as an empirical case study

258 As a study species, we focus on the small-bodied SPD, broadly endemic to western North

259 America and represented within all major drainage basins west of the Rocky Mountains. Its

260 distribution serves as a biodiversity bookmark for hydrography and geomorphology of western

261 North America (Hubbs and Miller 1948, Minckley et al. 1986, Oakey et al. 2004, Smith and

262 Dowling 2008). As such, it is remarkable adaptive, extending from high-altitude/ cold-water

263 streams of the Pacific Northwest (Pfrender et al. 2004, Hoekzema and Sidlauskas 2014), to

264 endorheic basins in the Mojave/ Sonoran deserts (Mussmann et al. 2020b). Extreme heat, aridity,

265 and salinity have not only extended its physiological limits but also diversified its phenotypic

266 evolution (Kaya et al. 1992, Lema 2014, Lema et al. 2019).

267

This extraordinary phylogenetic diversity also encompasses highly restricted habitats that

268 are vulnerable to stochastic and anthropogenic influences (Mussmann et al. 2020b).

269 Consequently, and as validated by history, it remains vulnerable to extinction, with two lineages

270 being contemporaneously eliminated in the $20^{\text {th }}$ century, and four subspecies listed under the

271 United States Endangered Species Act of 1973, as amended (16 U.S.C. 1531-1544, 87 Stat. 884).

272 This contemporary decline and extirpation underscores a vulnerability to ongoing climate change

273 (Minckley and Deacon 1968), an hypothesis we test herein by examining several summary

274 indices of anthropogenic modification, in addition to an array of environmental and hydrological

275 predictors (Table 1, and descriptions below). 


\subsection{1 | Sampling and data generation}

278 Fin tissues were collected for $N=762$ individuals distributed throughout 78 Colorado River Basin

279 localities $(\mu=9.8 /$ site) (Fig. 2; Table S1; Mussmann, 2018). Whole genomic DNA extractions

280 involved several methods (i.e., Gentra Puregene DNA Purification Tissue kit, QIAGEN DNeasy

281 Blood and Tissue kit, QIAGEN QIAamp Fast DNA Tissue Kit, or CsCl-gradient extraction).

282 These were subsequently quantified via Qubit fluorometer (Thermo Fisher Scientific, Inc.) and

283 assessed via gel electrophoresis (2.0\% agarose). Sequencing followed the ddRAD protocol

284 (Peterson et al. 2012), with restriction digest of $1 \mu \mathrm{g}$ DNA per sample using PstI and MspI

enzymes (New England Biolabs) at $37^{\circ} \mathrm{C}$ for 24 hours, followed by bead-purification (Agencourt

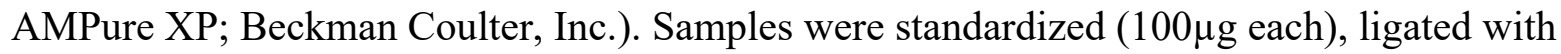

287 uniquely-barcoded adapters, then pooled into sets of $N=48 /$ library. These were size selected

288 (375-425bp; Sage Science Pippin Prep), then extendedn by PCR-based adapter (x12 cycles)

289 using Phusion high-fidelity DNA polymerase (New England Biolabs). Three uniquely-indexed

290 libraries (=144 samples total) were pooled per 1x100 base pair (bp) lane for sequencing on the

291 Illumina HiSeq 2000 (University of Wisconsin Biotechnology Center) or HiSeq 4000

292 (University of Oregon Genomics \& Cell Characterization Core Facility).

\subsection{2 | Data assembly and filtering}

295 Reads were demultiplexed and assembled using the process_radtags module (STACKS v2.41;

296 Rochette et al. 2019), followed by elimination of low-quality reads (Phred quality score $<20$ ),

297 uncalled bases, and missing restriction cut sites, while allowing one barcode mismatch.

298 Assembly was performed using de novo clustering in STACKS, with samples hierarchically

299 grouped into $N=5$ subregions: Upper Colorado River Basin $(N=221)$, Virgin River $(N=223)$, 
300 Grand Canyon and tributaries $(N=149)$, Gila River Basin $(N=105)$, and Little Colorado River

$301(N=64)$. This ensured recovery of informative loci within each region. Trial runs using STACKS

302 yielded optimal assembly parameters (Paris et al. 2017) for the minimum number of raw reads

303 necessary to form a stack $(\mathrm{m}=4)$, as well as the number of mismatches between stacks for

304 identification of putative loci $(M=2)$, and catalog formation $(n=2)$. The populations module was

305 utilized to identify SNPs shared by individuals located within a subregion, as outlined above.

306 Loci appearing in $<50 \%$ of individuals from each subregion were removed, as were loci with an

307 observed heterozygosity $>0.6$, and a minor allele frequency (MAF) $<0.01$. These measures

308 removed putative paralogs and minimally informative loci (Eaton 2014; McKinney et al. 2017).

\subsection{3 | SPD population structure}

311 To provide context for our analyses of riverscape resistance and genetic differentiation, we first

312 gauged population structure by employing an aspatial clustering method (ADMIXTURE;

313 Alexander et al. 2009). Data were filtered to one SNP/ locus, with samples partitioned by region.

314 To do so, we evaluated models containing $K=1-20$ possible sub-populations across 20 replicates,

315 executed in parallel (ADMIXPIPE pipeline; Mussmann et al. 2020a). Cross-validation (CV) values

316 were calculated in ADMIXTURE and summarized across replicates.

317 Replicates were clustered and evaluated in CLUMPAK (Kopelman et al. 2015) so as to

318 identify potentially discordant modes within a single $K$ value. Major clusters were identified

319 using a threshold of $90 \%$. Optimal $K$ represented the lowest CV value.

320 
322 To test environmental correlates of genetic differentiation, we examined 26 continuous

323 environmental and anthropogenic variables (see Table 1) per stream reach, as parsed from global

324 databases (Grill et al. 2019, Linke et al. 2019). Additional variables were removed from the

325 referenced databases if they exhibited a significant pairwise correlation coefficient (Pearson's $r$ )

$326>0.7$ (per Holm's multiple test correction; Holm 1979).

\subsubsection{Environmental associations and riverscape resistance}

329 We first calculated pairwise linearized $F_{\mathrm{ST}}\left(=F_{\mathrm{ST}} / 1-F_{\mathrm{ST}}\right)$ for each sampled SNP locus

330 (ADEGENET; Jombart 2008). These were input into DiSTNET using the --locmatdir and -r

331 RUNLOCI options. Samples were grouped by locality and, to maximize comparability with

332 StreAmTreE estimates (Kalinowski et al. 2008), the unweighted least-squares approach

333 (Cavalli-Sforza and Edwards 1967, Kalinowski et al. 2008) was employed to fit our stream trees.

334 We used the --iterative argument to correct for negative distances. For the input stream matrix,

335 we used a stream layer representing all of North America, as clipped from the RIVERATLAS

336 dataset (Linke et al. 2019). This was subsequently reduced to a minimal contiguous sub-network

337 by an automated procedure performed within DISTNET.

338 Output included a geodatabase and shapefile that mapped contiguous-edge IDs with the

339 original segment identifiers from RIVERATLAS (=HYRIV_ID), as well as fitted $F_{\text {ST }}$ values for

340 each locus assigned to each edge, and a mean/ standard deviation across all loci. We performed

341 an automated generalized linear mixed model selection procedure (GLMULTI; Calcagno and de

342 Mazancourt 2010) so as to first examine the relationship between the mean fitted distances and

343 the underlying environmental RIVERATLAS features (Table 1). A genetic algorithm was used to

344 explore all possible sets of explanatory variables, including pairwise interactions among 
345 variables. RVI values were computed using the sum of Akaike weights. Prior to analysis, all

346 variables were scaled, centered, and transformed to approximate normality (BESTNORMALIZE;

347 Peterson and Cavanaugh 2019). To consider the effect of variable dispersion, a second GLMULTI

348 run examined the coefficients of variation $\left(c_{v}\right)$ for raw values, calculated per network edge as the

349 ratio of the standard deviation among all contiguous stream reaches composing an edge by the

350 absolute value of the mean.

351 We then performed redundancy analysis (RDA), with the number of variables reduced

352 using a forward selection procedure with 10,000 permutations [ADESPATIAL; (Dray et al. 2018)].

353 The iterative selection procedure was halted using an adjusted $R^{2}$ threshold computed from a

354 global RDA using all variables (VEGAN; Oksanen et al 2007). A partial RDA (pRDA)

355 conditioned on edge lengths, was employed to 'partial-out' the IBD effects on $F_{\text {STs }}$ fitted edge-

356 wise. Significance was evaluated using the anova.cca() function in VEGAN, with outliers

357 identified as stream edges or SNPs having loadings $+/-3$ standard deviations from the mean, and

358 labelled according to the predictor variable having the greatest correlation.

The above methods examined the correlation of fitted distances versus edgewise

360 environmental variables in the stream network. As contrast, we also applied the RESISTNET

361 approach using raw values to compensate for the internal optimization, transformation and

362 scaling of variables. Four replicates were employed, with population sizes equating to either 288

363 or 512. Exploratory analyses were used to tune mutation (mutpb and indpb) and crossover (cxpb)

364 parameters, and to benchmark runtime. The maximum number of generations for full runs was

365 set at 500, with a stop-criterion (=50 generations) engaged if indeed the best model (nfail) failed

366 to improve. All transformation types were allowed, and variables weights ranged from 0 -1. Input

367 represented the optimized graph and outputs from DiSTNET. 


\section{RESULTS (1414)}

\section{1 | Data assembly and population structure}

370 The global assembly represented 13,218 loci at $25.94 x$ mean depth of coverage, with $27.6 \%$

371 missing data after those loci present in $<50 \%$ of individuals were removed. ADMIXTURE

372 identified $K=30$ populations summed across the five a priori defined sub-basins (Fig. 3 ). The

373 Upper Colorado River Basin was divided into $K=6$ groups composed of major tributaries: Chinle

374 Wash, Green River, Paria River, San Juan River, Smiths Fork River, and Vermillion Creek, with

375 the San Juan River encompassing the Fremont and San Rafael rivers. The Virgin River Basin

376 was partitioned into $K=7$ sub-populations: Pluvial White River, Pahranagat River, Moapa River,

377 Meadow Valley Wash, Beaver Dam Wash headwaters, and Virgin River headwater/ mainstem

378 (Fig. 3). Of note, two localities contain unique SPD subspecies: Pahranagat (R. o. velifer), and

379 Moapa (R. o. moapae).

380 The remaining $K=17$ sub-populations were distributed throughout the Lower Colorado

381 River Basin, with $K=5$ being distributed linearly through the Grand Canyon (Fig. 3). The

382 remainder were divided among the Bill Williams River $(K=1)$, Little Colorado River $(K=4)$, and

383 Gila River $(K=7)$. The latter was also represented by major tributaries and stream hierarchy:

384 Agua Fria, Eagle Creek, San Francisco River, San Pedro River, San Simon River, Verde River, 385 and Upper Gila tributaries (Fig. 3).

\section{2 | Stream hierarchy via DISTNET}

388 The minimal graph from DISTNET contained 114 edges representing contiguous combinations of

389 stream reaches, with nodes either as sampling localities or the minimum number of necessary

390 junctions required for shortest Dijkstra paths (Fig. S2). Fitted, linearized $F_{\text {ST }}$ for many mainstem 
391 reaches of the Colorado and Green rivers (globally over all loci; Fig. 4A) trended very low

$392\left(F_{\mathrm{ST}}=0.0-0.1\right)$. Elevated values $\left(F_{\mathrm{ST}}>0.2\right)$ were more common in the Lower Colorado River

393 Basin. For example, the Agua Fria and Bill Williams rivers both had values $>0.35$, with higher

394 values also found in multiple smaller tributaries (e.g., Salt River $>0.25$; Fig. 4A). Several inter-

395 drainage connections also displayed elevated values: Grand Canyon-Virgin River $(>0.15)$;

396 Grand Canyon-Little Colorado (>0.15); Lower Colorado-Gila River $(\sim=0.10)$. Few in the upper

397 Colorado River Basin tributaries had $F_{\mathrm{ST}}>0.1$, save for the North Fork of Vermillion Creek in

398 Wyoming $(>0.25)$.

Linearized $F_{\mathrm{ST}}$ for all SNP loci averaged across DISTNET (via $-r$ RUNLOCI) generally

401 basins were exceptions, with the Colorado River mainstem being slightly higher relative to the

402 median. The same was observed when examining standard deviation of per-locus fitted- $F_{\text {ST }}($ Fig.

403 4C), with slightly higher relative values in the segment connecting the Virgin-Muddy Basin with

404 the Colorado River in the Grand Canyon.

405 The majority of sampling localities were within $0-2 \mathrm{~km}$ of nodes in the input stream

406 network, suggesting scant effect due to 'snapping' error or missing stream segments (Fig. 4D).

407 The fit between predicted distances versus input $F_{\mathrm{ST}}$ was similar to that calculated in the original

408 STREAMTREE program (adjusted $R^{2}=0.77$ versus 0.787 ), again suggesting that slight differences

409 in implementation produced minimal error (Fig. 4E). Stream distances alone were also a

410 relatively poor predictor of $F_{\mathrm{ST}}$, particularly when compared with those predicted using the

411 STREAMTREE model (Mantel $r=0.47, p<0.001$; Linear model $R^{2}=0.22, p<0.01$; Fig. 4F). 


\subsection{1 | Testing correlates of fitted distances}

415 Generalized linear model (GLM) selection evaluated edgewise variable means $(\mu)$ and six

416 variables [via variation coefficients $\left(c_{v}\right)$ via GLMuLTi (Fig. 5B, Table 2)] so as to identify eight

417 variables at a model-averaged RVI threshold of 0.8 (Fig. 5A, Table 2). Two variables (i.e., USE

418 and TMP) exceeded $>0.8$ when both $\mu$ and $c_{v}$ were considered. Analysis of variable $\mu_{s}$ also

419 implicated three anthropogenic (POP, HDI, CSI), two hydrologic (RES, DOF), and one land-

420 cover variable (PAC). Additionally, model-averaged RVI for $c_{v}$ implicated ARI, SOC, and RIV

421 as well (Fig. 5A, Table 2).

422 Global RDA of stream-wise means were statistically significant $(p<0.001$, adjusted

$\left.423 R^{2}=0.127\right)$. Forward selection evaluated a minimum number of maximally discriminatory

424 variables and chose 10 that met the adjusted R-threshold. Implementing a correction for false-

425 discovery rate (FDR) via the Benjamini-Hochberg procedure resulted in four variables being

426 selected: AET, PET, USE, and DOF (Fig. 5B-E, Table 2). VIFs ranged from 1.19-1.88, and both

427 RDA and partial RDA were significant for the selected variables $(p<0.001)$ (with pRDA

428 conditioned on LENGTH). The pRDA designated 221 SNPs (Figs. B-C) and 9 edges (Figs. D-E)

429 as outliers, with the largest proportion having the strongest direct correlations with evapo-

430 transpiration (AET/ PET; Table S2).

431 Stream-wise variation coefficients from the global RDA were also significant $(p=0.007$,

$432 R^{2}=0.12$ ), with four variables chosen via forward selection: PET, SOC, SLP, and CSI (Figs. 5F-I,

433 Table 2). Both RDA and pRDA for the selected variables remained significant $(p<0.001)$, with

434 VIFs ranging between 1.04-1.21. Based on pRDA loadings, 349 SNPs (Figs. 5F-G) and eight

435 edges were identified as outliers (Figs. 5H-I), with outlier associations most prevalent for SOC

436 and PET (Table S2). 


\subsection{2 | The optimization of resistance models}

439 We ran four replicate RESISTNET analyses within two different computing environments:

440 Replicates 1 and 2 done virtually on the JETSTREAM cloud (Hancock et al. 2018), while 3 and 4

441 were on Linux-based high-performance compute (HPC) nodes in the TRESTLES cluster at

442 University of Arkansas. We also varied the population size from $\mathrm{N}=288$ (for 1 and 3 ) to $\mathrm{N}=512$

443 (2 and 4).

All replicates running the complete SPD dataset terminated in $<24$ hours, with an

445 increase in mutpb and indpb parameters that controlled the probability of individual models and

446 parameters being selected for random mutation. This is necessary step in that rates of mutation

447 (mutpb and indpb) and crossover $(c x p b)$ will vary as a function of parameter space and

448 population size. Here, we recommend these parameters be tuned a priori so as to promote mixing

449 and prevent stationarity.

$450 \quad$ Parallelization was examined during exploratory runs and yielded non-linear

451 improvement with increasing numbers of dedicated processor cores. We saw $\sim 3.5 \mathrm{X}$ speed-up

452 going from 1 to 4 processors, whereas increasing from 1 to 16 processors yielded $\sim 10 \mathrm{X}$

453 improvement (Fig. S3). Even so, we found this to provide a substantial performance benefit over

454 dedicating additional threads to parallel processing by CIRCUITSCAPE (Fig. S4), thus we advise

455 complete CPU utilization should be dedicated to distributing genetic algorithm evaluations by

456 RESISTNET (supplied using the - procs command-line argument).

457 Full analyses at $\mathrm{N}=288$ or 512 met stopping criteria in $\sim 60-70$ generations and

458 demonstrated a fairly rapid plateau in fitness (Fig. S5). The 'best' models in each replicate run

459 varied in fitness, with a moderate predictive capacity as indicated in the MLPE mixed effects 
models (marginal $R^{2}=0.296-0.343$ ). Model-averaged effective resistance networks were similar across all replicates, with streams in the Virgin, Gila, and Little Colorado River sub-basins

462 generally having greatest resistance, with the lowest being found in upper Green River tributaries

463 and the mainstem Colorado River above the Grand Canyon (Fig. 6A). Some smaller tributaries in 464 the Upper Colorado River Basin also had high relative resistance values, such as tributaries of

465 the San Juan (i.e., mainstem of Chinle Wash and the Mancos River), and tributaries of the Green 466 River (i.e., Vermillion Creek, and the White River).

Individual replicates were also largely consistent with regard to environmental covariates 468 that defined the composite resistance models, as selected for averaging: ARI, CRP, DOR, PAC, 469 PET, SED, and USE in all four replicates (=100\%), whereas SOC and URB were in 75\% (Table 470 2). The remainder (i.e., AET, POP, SGR, SLP) were present in 50\% of replicates (Table 2).

471 However, those streams that failed to select catchment slope (SLP) as a covariate, did so instead 472 with stream gradient (SGR), which we interpret as a functional equivalent. Three additional 473 covariates (i.e., DOF, PST, RDD) were selected but once, with generally low model-averaged 474 weights $(0.08-0.42)$.

475 Model-averaged resistance values were highly correlated among replicates (Pearson's $476 r=0.69-0.96$; Fig. 6C), with Replicate 2 having the greatest discordance. Of note, this replicate 477 converged on the highest likelihood model (Fig. S5) and also a replicate that that optimized the 478 larger model population $(\mathrm{N}=512)$, potentially highlighting the necessity of a greater population 479 size so as to identify global fitness maxima. Pairwise effective resistances among sites for each 480 replicate were likewise highly consistent (Mantel $r=0.94-0.99$ ), with all being highly significant $481 \quad(p<0.0001$; Fig. 6C). 


\section{DISCUSSION (1669)}

484 Spatio-genetic patterns in landscape and riverscape genetics must first be defined before

485 hypotheses can be tested regarding habitat availability, inherent barriers, and potential corridors.

486 Yet, most methods common to riverscape genetics, for example, fail to consider network

487 architecture (Davis et al. 2018), or those attributes that define paths through which individuals

488 must travel. The analytical framework we provide serves to characterize the manner by which

489 genetic diversity and network topology juxtapose, and does so by mapping multi-locus distances

490 onto habitat edges, with causation then explored in a heuristic but rigorous manner. In so doing,

491 we examine an arbitrary number of covariates by employing an explicit graph structure,

492 accomplished without designating variable weighting or a priori candidate models.

493 The utility of our approach is underscored by its application in a case study involving

494 SPD in the Colorado River Basin. For some tributaries, highly-fitted $F_{\text {ST }}$ (Fig. 3) and high

495 resistance in multiple sub-basins (Fig. 6) indicate the elevated divergence of isolated lineages,

496 even within relatively well-connected riverscapes. Interestingly, segment length was often non-

497 explanatory with regards to basin-wide genetic diversity (e.g., Table 2), implicating a loss of

498 connectivity as more important with regard to intraspecific divergences. This, in turn, juxtaposes

499 well with the prevalence of unique and relictual lineages within isolated watersheds (Oakey et al.

500 2004, Mussmann et al. 2020b).

501 Connectivity was likewise implicated as an important factor for consistent recovery of

502 covariates linked to drought tolerance and seasonal persistence of streams (e.g., AET, ARI,

503 PET). Additionally, the dominant association of these variables with outlier loci (Table S2, Fig.

504 5), suggests the presence of local adaptation with regard to ephemeral flow regimes. Hydrology

505 has similarly been implicated as a driver of morphological diversification in numerous 
506 freshwater systems (Langerhans 2008, Meyers and Belk 2014, Bruckerhoff and Magoulick

507 2017), and its importance in sustaining native fish assemblages has been documented across

508 southwestern streams (Propst and Gido 2004, Probst et al. 2008, Kominoski et al. 2018). The

509 large weights attributed to those variables that define stream persistence clearly reflect the

510 impacts of aridity and persistent drought in the region, both of which are omnipresent across

511 contemporary desert riverscapes (Kingsford 2006, Ruhí et al. 2015).

512 Covariates relating to contemporary (e.g., anthropogenic) water manipulation and stream

513 fragmentation were also repeatedly chosen across analyses. Here, factors such as the prevalence

514 of anthropogenic land-use categories [e.g., cropland (CRP); urban extent (UBR)], as well as

515 multiple indices of hydrologic manipulation [e.g., water usage (USE); degree of regulation

516 (DOR); sedimentation rate (SED)], consistently contributed to composite resistance models (Fig.

517 6; Table 2). Several of these are functionally-related, such as: Agricultural/ urban areas as major

518 drivers of water usage (USE); flow regulation/ flood dampening (DOR) as controlling sediment

519 supply (SED) as well as channel width and morphology (Grams et al. 2020, Walker et al. 2020).

520 Anthropogenic factors that promote habitat instability in the Colorado River also

521 contribute significantly to the permeability of species boundaries in endemic cyprinids, with

522 population demographic and genetic trends being impacted (Chafin et al. 2019). These altered

523 conditions may also change the distribution and suitability of low-flow refugia, serving in turn to

524 extirpate peripheral populations (Schlosser 1995, Bezzerides and Bestgen 2002, Magoulick and

525 Kobza 2003). Altered conditions also promote the establishment of non-native species (Gido and

526 Propst 1999, Whitney et al. 2017, Dibble et al. 2020), which may in turn elevate predation rates

527 and promote competition (Marsh and Douglas 1997, Seegert et al. 2014). Predation pressure by 
528 resident fishes also constrains the invasion success of introduced SPD (Harvey et al. 2004), thus

529 suggesting a potential role for non-natives in promoting 'biotic' resistance.

\subsection{Stream hierarchy and riverscape resistance models}

532 Our case study demonstrates both the utility and limitations of the DiSTNET and RESISTNET

533 approaches. Before each can be applied, a necessary understanding is required of how historical

534 factors such as shifting distributions may also impact results. For example, the optimization of a

535 resistance model will be poor when 'true' correlation among genetic and resistance distances is

536 low (Winiarski et al. 2020). Another implicit assumption is that genetic divergences are

537 attributable to the edges within the network (Kalinowski et al. 2008). A potential example of

538 where this might fail could be admixture involving unsampled lineages. For example, Minckley

539 (1973) suggested that intergradation between morphological forms of SPD in the Little Colorado

540 and Gila river drainages was driven by historic stream capture along the Mogollon Rim, with

541 historically-transient connections possible as well between some Upper Colorado River Basin

542 tributaries and those of the Bear or Snake rivers (Smith and Dowling 2008, Loxterman and

543 Keeley 2012). Historic reticulation violates an assumption of our resistance model, in that

544 connectivity does not involve edges external to the network.

545 As with landscape genetic studies, individual movements via extremely rare natural

546 connection or human-mediated translocations will also bias result by altering spatio-genetic

547 associations (Chafin et al., 2021). However, these occurrences could potentially be adjusted for

548 by adding additional edges as historic connections, under the assumption that a priori hypotheses

549 can be formulated. Inflated genetic divergences may also emerge as vestiges of historic barriers,

550 such as vicariant Pleistocene lava flows that separate the upstream Little Colorado River from 
551 the Grand Canyon (Duffield et al. 2006). If indeed unrecognized, then $F_{\text {ST-values fitted along }}$

552 that stretch would be incorrectly inflated. Historic population dynamics could also lead to a

553 situation where genetic divergences fail to juxtapose with extant conditions, which may explain

554 the high divergence displayed by Vermillion Creek, which may have inadvertently escaped

555 large-scale, indiscriminate rotenone poisoning in the 1950s-60s as a mechanism to exterminate

556 non-native species in the Green River (Holden 1991). Finally, it is also possible that

557 environmental and/ or anthropogenic components of riverscape resistance may vary at smaller

558 spatial scales, especially in those species widely-distributed. Here, a mechanism of test is

559 provided in RESISTNET as an analysis partitioned by sub-basin. The relationship between

560 particular covariates and resistance may often be non-linear, or instead drive resistance as a

561 function of variance (e.g., depth or flow within a reach), rather than by per-edge means (as were

562 examined in resistance models herein). A contrast between variation coefficients and the GLM

563 results of edge means could lends weight to the latter. Non-linear interactions are evaluated in

564 RESISTNET via the simultaneous optimization of variable transformation and shape parameters,

565 yet this remains a limitation in the post hoc analysis of DiSTNET results (as herein) and may

566 explain why numerous covariates were implicated in the resistance models. Alternate

567 aggregation methods (e.g., variation coefficients) could also be employed with RESISTNET,

568 although they are not currently integrated at this point.

These limitations serve as a necessary context from which to develop additional

570 applications, or as avenues for future research, as do emerging developments in riverscape

571 genetics (i.e., this study and White et al., 2020). One extension for locus-wise analysis (as

572 demonstrated herein with RDA; Fig. 5), is the identification of functional genomic associations

573 that can promote isolation-by-adaptation rather than environmental resistance or limitation via 
574 dispersal (Orsini et al. 2013). Adaptive genetic variation is a relatively underexplored theme in

575 riverscape genetics (Davis et al. 2018), due largely to a dearth of methods that detect 'outlier'

576 loci within the autocorrelative structure of dendritic networks. Thus, to this end, we hope that a

577 broader exploration of adaptive patterns in riverscapes can be facilitated multi-locus fitting in

578 DistNeT.

Another advantage of the RESISTNET is the potential to extrapolate and predict genetic

580 responses in unsampled space. Here, optimized resistance models may be applied to any

581 dendritic ecological network (to include riverscapes, as herein), so as to predict effective

582 resistance in regions within which genetic data has yet to be obtained. This could promote $a$

583 priori hypotheses of population structure and phylogeography that serve to predict transecting

584 regions with elevated divergences, or inform analyses requiring assignment priors (Hubisz et al.

585 2009). The resulting contrasts between hypothesized and observed divergences may also target

586 sub-drainages within which discordance has been driven by historical processes.

588 forged by contemporary data then used to extrapolate metapopulation dynamics under conditions

589 predicted due to climate change or other disturbance (Comte and Grenouillet 2013, Comte and

590 Olden 2017). Importantly, the approach could also be applied to any type of pairwise distance

591 matrix. For example, DistNeT could employ community data to examine edge-wise distances or

592 topological importance in generating differences (Eros et al. 2011), whereas RESISTNET could be

593 used to examine how metacommunity structure is defined by environmental resistance. Again,

594 any form of spatially structured ecological network can be generalized to accommodate either.

595 The potential of DISTNET and RESISTNET for increased automation also serves to

596 encourage large-scale comparative riverscape studies involve variation among species in spatial 
597 or temporal trends, the results of which could vary substantially as a function of trait synergism

598 or life histories (Comte et al. 2014, McManamay and Frimpong 2015, Troia et al. 2019). While

599 rare, such intraspecific studies have implicated ongoing evolution within dendritic networks,

600 while testing specific ecological questions (Fourtune et al. 2016, Pilger et al. 2017, Paz-Vinas et

601 al. 2018, Blanchet et al. 2020). For example: Why do some species exhibit greater intraspecific

602 variation in functional/ morphological attributes than do co-occurring species? (Raffard et al.

603 2020). How might traits or life histories shape this contrast? How do these patterns relate to

604 long-term macroevolutionary trends (Singhal et al. 2018, Harvey et al. 2019)? Further, a

605 comparative framework also promotes an examination of those commonalities driving

606 community-level structure or shared biogeographic breaks, which may in turn yield trends

607 generalizable to conservation planning at contemporary spatial or taxonomic scales (Linke et al.

608 2011, Paz-Vinas et al. 2018), and which can effectively promote multi-species management

609 objectives (Nielsen et al. 2017; Douglas et al. 2020).

\section{ACKNOWLEDGEMENTS}

612 We thank Z.D. Zbinden and B.T. Martin for helpful discussions, including invaluable advice

613 with regards to statistical and analytical procedures. We also recognize the Arkansas High

614 Performance Computing Center for computational resources that allowed this package to be

615 tested on the Trestles cluster at University of Arkansas, as funded through multiple National

616 Science Foundation grants and the Arkansas Economic Development Commission. Additional

617 computation support was provided by the NSF XSEDE Jetstream cloud via an allocation

618 awarded to TKC (TG-BIO200074). This work was also indirectly supported by University of

619 Arkansas doctoral fellowships (TKC, SMM, ZDZ), and endowments (MED: $21^{\text {st }}$ Century Global 
620 Change Biology Chair; MRD: Bruker Life Sciences Professorship). TKC is supported by an NSF

621 Postdoctoral Fellowship in Biology under Grant No. DBI: 2010774. The use of trade, product,

622 industry or firm names is for informative purposes only and does not constitute an endorsement

623 by the U.S. Government or the U.S. Fish and Wildlife Service (USFWS). Links to non-Service

624 Web sites do not imply official USFWS endorsement of opinions or ideas expressed therein or

625 guarantee the validity of the information provided. The findings, conclusions, and opinions

626 expressed in this article represent those of the authors, and do not necessarily represent the views

627 of the USFWS, NSF, nor any other funding or affiliated organizations.

629 Data Accessibility Statement

630 Raw FASTQ files for each individual have been uploaded to the NCBI Sequence Read Archive

631 (BioProject ID PRJNA656098) and will be released to the public upon publication. All code is

632 available open-source at: github.com/tkchafin/DENdriscape. Curated alignment files and inputs

633 will be made available via the Open Science Framework (DOI: XXXXX) following acceptance. 


\section{REFERENCES}

635

Alexander, D. H., J. Novembre, and K. Lange. 2009. Fast model-based estimation of ancestry in unrelated individuals. Genome Research 19:1655-1664.

Altermatt, F., and E. A. Fronhofer. 2018. Dispersal in dendritic networks: Ecological consequences on the spatial distribution of population densities. Freshwater Biology 63:2232 .

Baggio, R. A., S. B. L. Araujo, D. Ayllón, and W. A. Boeger. 2018. Dams cause genetic homogenization in populations of fish that present homing behavior: Evidence from a demogenetic individual-based model. Ecological Modelling 384:209-220.

Bezzerides, N., and K. Bestgen. 2002. Status review of Roundtail chub (Gila robusta), Flannelmouth sucker (Catostomus latipinnis), and Bluehead sucker (Catostomus discobolus) in the Colorado River Basin. Final report to the U.S. Bureau of Reclamation.

Blanchet, S., J. G. Prunier, I. Paz-Vinas, K. Saint-Pé, O. Rey, A. Raffard, E. Mathieu-Bégné, G. Loot, L. Fourtune, and V. Dubut. 2020. A river runs through it: The causes, consequences, and management of intraspecific diversity in river networks. Evolutionary Applications 13:1195-1213.

Bradbury, I. R., and P. Bentzen. 2007. Non-linear genetic isolation by distance: Implications for dispersal estimation in anadromous and marine fish populations. Marine Ecology Progress Series 340:245-257.

Brauer, C. J., and L. B. Beheregaray. 2020. Recent and rapid anthropogenic habitat fragmentation increases extinction risk for freshwater biodiversity. Evolutionary Applications 13:2857-2869.

Brauer, C. J., M. P. Hammer, and L. B. Beheregaray. 2016. Riverscape genomics of a threatened fish across a hydroclimatically heterogeneous river basin. Molecular Ecology 61:50935113.

Brauer, C. J., P. J. Unmack, S. Smith, L. Bernatchez, and L. B. Beheregaray. 2018. On the roles of landscape heterogeneity and environmental variation in determining population genomic structure in a dendritic system. Molecular Ecology 27:3484-3497.

Bruckerhoff, L. A., and D. D. Magoulick. 2017. Hydrologic regimes as potential drivers of morphologic divergence in fish. Evolutionary Ecology 31:517-531.

Calcagno, V., and C. de Mazancourt. 2010. glmulti: An R package for easy automated model selection with (generalized) linear models. Journal of Statistical Software 34:29.

Camak, D. T., and K. R. Piller. 2018. Going with the flow: Testing the role of habitat isolation among three ecologically divergent darter species. Copeia 106:375-387.

Campbell Grant, E. H. 2011. Structural complexity, movement bias, and metapopulation extinction risk in dendritic ecological networks. Journal of the North American Benthological Society 30:252-258.

Campbell Grant, E. H., W. H. Lowe, and W. F. Fagan. 2007. Living in the branches: Population dynamics and ecological processes in dendritic networks. Ecology Letters 10:165-175. 
Cavalli-Sforza, L. L., and A. W. Edwards. 1967. Phylogenetic analysis. Models and estimation procedures. American Journal of Human Genetics 19:550-570.

Cavalli-Sforza, L. L., and A. Piazza. 1975. Analysis of evolution: Evolutionary rates, independence and treeness. Theoretical Population Biology 8:127-165. Ballard, and M. E. Douglas. 2021. Spatial population genetics in heavily managed species: Separating patterns of historical translocation from contemporary gene flow in white-tailed deer. Evolutionary Applications In Press.

682

Chafin, T. K., M. R. Douglas, B. T. Martin, and M. E. Douglas. 2019. Hybridization drives genetic erosion in sympatric desert fishes of western North America. Heredity 123:759773.

Chiu, M. C., B. Li, K. Nukazawa, V. H. Resh, T. Carvajal, and K. Watanabe. 2020a. Branching networks can have opposing influences on genetic variation in riverine metapopulations. Diversity and Distributions 26:1813-1824.

Chiu, M. C., K. Nukazawa, T. Carvajal, V. H. Resh, B. Li, and K. Watanabe. 2020b. Simulation modeling reveals the evolutionary role of landscape shape and species dispersal on genetic variation within a metapopulation. Ecography 43:1891-1901.

Coleman, R. A., B. Gauffre, A. Pavlova, L. B. Beheregaray, J. Kearns, J. Lyon, M. Sasaki, R. small isolated populations of a low-mobility freshwater fish. Heredity 120:515-532.

Comte, L., and G. Grenouillet. 2013. Do stream fish track climate change? Assessing distribution

Comte, L., J. Murienne, and G. Grenouillet. 2014. Species traits and phylogenetic conservatism shifts in recent decades. Ecography 36:1236-1246. of climate-induced range shifts in stream fishes. Nature Communications 5:5053.

Comte, L., and J. D. Olden. 2017. Climatic vulnerability of the world's freshwater and marine fishes. Nature Climate Change 7:718-722.

Cooke, G. M., E. L. Landguth, and L. B. Beheregaray. 2014. Riverscape genetics identifies replicated ecological divergence across an Amazonian ecotone. Evolution 68:1947-1960.

Davis, C. D., C. W. Epps, R. L. Flitcroft, and M. A. Banks. 2018. Refining and defining riverscape genetics: How rivers influence population genetic structure. Wiley Interdisciplinary Reviews: Water 5:e1269.

Dibble, K. L., C. B. Yackulic, J. C. Schmidt, T. A. Kennedy, and K. R. Bestgen. 2020. Water storage decisions will determine the distribution and persistence of imperiled river fishes. Ecological Applications.

Dijkstra, E. W. 1959. A note on two problems in connexion with graphs. Numerische Mathematik 1:269-271.

Douglas, M. E., and J. A. Endler. 1982. Quantitative matrix comparisons in ecological and evolutionary investigations. Journal of Theoretical Biology 99:777-795

Douglas, M. E., and W. J. Matthews. 1992. Does morphology predict ecology? Hypothesis testing within a freshwater stream fish assemblage. Oikos 65:213. 
Douglas, M. E., W. L. Minckley, and B. D. DeMarais. 1999. Did vicariance mold phenotypes of western North American fishes? Evidence from Gila River cyprinids. Evolution 53:238246.

Douglas, M. R., W. J. B. Anthonysamy, S. M. Mussmann, M. A. Davis, W. Louis, and M. E. Douglas. 2020. Multi-targeted management of upland game birds at the agroecosystem interface in midwestern North America. PLoS ONE 15(4): e0230735

Dray, S., G. Blanchet, D. Borcard, G. Guenard, T. Jombart, G. Larocque, P. Legendre, N. Madi, and H. H. Wagner. 2018. Package 'adespatial'. R package version, 3-8.

Duffield, W., N. Riggs, D. Kaufman, D. Champion, C. Fenton, S. Forman, W. McIntosh, R. Hereford, J. Plescia, and M. Ort. 2006. Multiple constraints on the age of a Pleistocene lava dam across the Little Colorado River at Grand Falls, Arizona. GSA Bulletin 118:421-429.

Eaton, D. A. 2014. PyRAD: assembly of de novo RADseq loci for phylogenetic analyses. Bioinformatics, 30:1844-1849.

Eros, T., D. Schmera, and R. S. Schick. 2011. Network thinking in riverscape conservation - A graph-based approach. Biological Conservation 144:184-192.

Fagan, W. F. 2002. Connectivity, fragmentation, and extinction risk in dendritic metapopulations. Ecology 83:3243-3249.

Fagan, W., P. Unmack, C. Burgess, and W. Minckley. 2002. Rarity, fragmentation, and extinction risk in desert fishes. Ecology 82:3250-3256.

Falke, J. A., L. L. Bailey, K. D. Fausch, and K. R. Bestgen. 2012. Colonization and extinction in dynamic habitats: An occupancy approach for a Great Plains stream fish assemblage. Ecology 93:858-867.

Felsenstein, J. 2004. Inferring phylogenies. Sinauer associates Sunderland, MA.

Fitch, W. M., and E. Margoliash. 1967. Construction of phylogenetic trees.

Fourtune, L., I. Paz-Vinas, G. Loot, J. G. Prunier, and S. Blanchet. 2016. Lessons from the fish: a multi-species analysis reveals common processes underlying similar species-genetic diversity correlations. Freshwater Biology 61:1830-1845.

Fraser, G. S., K. R. Bestgen, D. L. Winkelman, and K. G. Thompson. 2019. Temperature-not flow-predicts native fish reproduction with implications for climate change. Transactions of the American Fisheries Society 148:509-527.

Frissell, C. A., W. J. Liss, C. E. Warren, and M. D. Hurley. 1986. A hierarchical framework for stream habitat classification: Viewing streams in a watershed context. Environmental Management 10:199-214.

Fullerton, A. H., K. M. Burnett, E. A. Steel, R. L. Flitcroft, G. R. Pess, B. E. Feist, C. E. Torgersen, D. J. Miller, and B. L. Sanderson. 2010. Hydrological connectivity for riverine fish: Measurement challenges and research opportunities. Freshwater Biology 55:22152237.

Galbraith, H. S., D. T. Zanatta, and C. C. Wilson. 2015. Comparative analysis of riverscape genetic structure in rare, threatened and common freshwater mussels. Conservation Genetics 16:845-857. 
Gido, K. B., and D. L. Propst. 1999. Habitat use and association of native and nonnative fishes in the San Juan River, New Mexico and Utah. Copeia:321-332.

Grams, P. E., D. J. Dean, A. E. Walker, A. Kasprak, and J. C. Schmidt. 2020. The roles of flood magnitude and duration in controlling channel width and complexity on the Green River in Canyonlands, Utah, USA. Geomorphology 371:107438.

Grill, G., B. Lehner, M. Thieme, B. Geenen, D. Tickner, F. Antonelli, S. Babu, P. Borrelli, L. Cheng, H. Crochetiere, H. Ehalt Macedo, R. Filgueiras, M. Goichot, J. Higgins, Z. Hogan, B. Lip, M. E. McClain, J. Meng, M. Mulligan, C. Nilsson, J. D. Olden, J. J. Opperman, P. Petry, C. Reidy Liermann, L. Sáenz, S. Salinas-Rodríguez, P. Schelle, R. J. P. Schmitt, J. Snider, F. Tan, K. Tockner, P. H. Valdujo, A. van Soesbergen, and C. Zarfl. 2019. Mapping the world's free-flowing rivers. Nature 569:215-221.

Grummer, J. A., L. B. Beheregaray, L. Bernatchez, B. K. Hand, G. Luikart, S. R. Narum, and E. B. Taylor. 2019. Aquatic landscape genomics and environmental effects on genetic variation. Trends in Ecology \& Evolution 34:641-654.

Hagberg, A. A., D. A. Schult, and P. J. Swart. 2008. Exploring network structure, dynamics, and function using NetworkX. 7th Python in Science Conference (SciPy 2008).

Hancock, D. Y., C. A. Stewart, M. Vaughn, J. Fischer, J. M. Lowe, G. Turner, T. L. Swetnam, T. K. Chafin, E. Afgan, M. E. Pierce, and W. Snapp-Childs. 2018. Jetstream-Early operations performance, adoption, and impacts. Concurrency and Computation: Practice and Experience:e4683.

Harvey, B. C., J. L. White, and R. J. Nakamoto. 2004. An emergent multiple predator effect may enhance biotic resistance in a stream fish assemblage. Ecology 85:127-133.

Harvey, E., M. G. Harvey, S. Singhal, and D. L. Rabosky. 2019. Beyond reproductive isolation : demographic controls on the speciation process 50:75-95.

Hedrick, P. W. 2005. A standardized genetic differentiation measure. Evolution 59:1633-1638.

Hoekzema, K., and B. L. Sidlauskas. 2014. Molecular phylogenetics and microsatellite analysis reveal cryptic species of speckled dace (Cyprinidae: Rhinichthys osculus) in Oregon's Great Basin. Molecular Phylogenetics and Evolution 77:238-250.

Holden, P. B. 1991. Ghosts of the Green River: impacts of Green River poisoning on management of native fishes. Eds: Minckley, W. L., and J. E. Deacon. Battle against extinction. University of Arizona Press, Tuscon, AZ.

Hopken, M. W., M. R. Douglas, and M. E. Douglas. 2013. Stream hierarchy defines riverscape genetics of a North American desert fish. Molecular Ecology 22:956-971.

Hubbs, C. L. 1941. The relation of hydrological conditions to speciation in fishes. A Symposium in Hydrobiology 1941:182-195.

Hubbs, C. L., and R. R. Miller. 1948. The zoological evidence: correlation between fish distribution and hydrogeographic history in the desert basin of western North America. Bulletin of the University of Utah 10:17-166.

Hubisz, M. J., D. Falush, M. Stephens, and J. K. Pritchard. 2009. Inferring weak population structure with the assistance of sample group information. Molecular Ecology Resources 
9:1322-1332.

Hughes, J. M., D. J. Schmidt, and D. S. Finn. 2009. Genes in streams: Using DNA to understand the movement of freshwater fauna and their riverine habitat. BioScience 59:573-583.

Hutchison, D. W., and A. R. Templeton. 1999. Correlation of pairwise genetic and geographic distance measures: Inferring the relative influences of gene flow and drift on the distribution of genetic variability. Evolution 53:1898-1914.

Jackson, D. A., P. R. Peres-Neto, and J. D. Olden. 2001. What controls who is where in freshwater fish communities - The roles of biotic, abiotic, and spatial factors. Canadian Journal of Fisheries and Aquatic Sciences 58:157-170.

Jombart, T. 2008. Adegenet: A R package for the multivariate analysis of genetic markers. Bioinformatics 24:1403-1405.

Jost, L. 2008. GST and its relatives do not measure differentiation. Molecular Ecology 17:40154026.

Kalinowski, S. T., M. H. Meeuwig, S. R. Narum, and M. L. Taper. 2008. Stream trees : a statistical method for mapping genetic differences between populations of freshwater organisms to the sections of streams that connect them. Canadian journal of fisheries and aquatic sciences 65:2752-2760.

Kanno, Y., J. C. Vokoun, and B. H. Letcher. 2011. Fine-scale population structure and riverscape genetics of brook trout (Salvelinus fontinalis) distributed continuously along headwater channel networks. Molecular Ecology 20:3711-3729.

Kaya, C. M., P. F. Brussard, D. G. Cameron, and E. R. Vyse. 1992. Biochemical genetics and thermal tolerances of Kendall Warm Springs Dace (Rhinichthys osculus thermalis) and Green River Speckled Dace (R. o. yarrowi). Copeia 1992:528.

Keis, M., J. Remm, S. Y. W. Ho, J. Davison, E. Tammeleht, I. L. Tumanov, A. P. Saveljev, P. Männil, I. Kojola, A. V. Abramov, T. Margus, and U. Saarma. 2013. Complete mitochondrial genomes and a novel spatial genetic method reveal cryptic phylogeographical structure and migration patterns among brown bears in north-western Eurasia. Journal of Biogeography 40:915-927.

Kimmig, S. E., J. Beninde, M. Brandt, A. Schleimer, S. Kramer-Schadt, H. Hofer, K. Börner, C. Schulze, U. Wittstatt, M. Heddergott, T. Halczok, C. Staubach, and A. C. Frantz. 2020. Beyond the landscape: Resistance modelling infers physical and behavioural gene flow barriers to a mobile carnivore across a metropolitan area. Molecular Ecology 29:466-484.

Kingsford, R. 2006. Ecology of desert rivers. Cambridge University Press, Cambridge, UK.

Kominoski, J. S., A. Ruhí, M. M. Hagler, K. Petersen, J. L. Sabo, T. Sinha, A. Sankarasubramanian, and J. D. Olden. 2018. Patterns and drivers of fish extirpations in rivers of the American Southwest and Southeast. Global Change Biology 24:1175-1185.

Kopelman, N. M., J. Mayzel, M. Jakobsson, N. A. Rosenberg, and I. Mayrose. 2015. Clumpak: a program for identifying clustering modes and packaging population structure inferences across K. Molecular ecology resources 15:1179-1191.

Labonne, J., V. Ravigné, B. Parisi, and C. Gaucherel. 2008. Linking dendritic network structures 
to population demogenetics: The downside of connectivity. Oikos 117:1479-1490.

Langerhans, R. B. 2008. Predictability of phenotypic differentiation across flow regimes in fishes. Integrative and Comparative Biology 48:750-768.

Legendre, P., M.-J. Fortin, and D. Borcard. 2015. Should the Mantel test be used in spatial analysis? Methods in Ecology and Evolution 6:1239-1247.

Legendre, P., and M. J. Fortin. 2010. Comparison of the Mantel test and alternative approaches for detecting complex multivariate relationships in the spatial analysis of genetic data. Molecular Ecology Resources 10:831-844.

Lema, S. C. 2014. Hormones and phenotypic plasticity in an ecological context: Linking physiological mechanisms to evolutionary processes. Integrative and Comparative Biology $54: 850-863$.

Lema, S. C., S. L. Bock, M. M. Malley, and E. A. Elkins. 2019. Warming waters beget smaller fish: Evidence for reduced size and altered morphology in a desert fish following anthropogenic temperature change. Biology Letters 15:20190518.

Linke, S., B. Lehner, C. Ouellet Dallaire, J. Ariwi, G. Grill, M. Anand, P. Beames, V. BurchardLevine, S. Maxwell, H. Moidu, F. Tan, and M. Thieme. 2019. Global hydro-environmental sub-basin and river reach characteristics at high spatial resolution. Scientific data 6:283.

Linke, S., E. Turak, and J. Nel. 2011. Freshwater conservation planning: The case for systematic approaches. Freshwater Biology 56:6-20.

Lowe, W. H., and D. T. Bolger. 2002. Local and landscape-scale predictors of salamander abundance in New Hampshire headwater streams. Conservation Biology 16:183-193.

Lowe, W. H., G. E. Likens, M. A. McPeek, and D. C. Buso. 2006. Linking direct and indirect data on dispersal: Isolation by slope in a headwater stream salamander. Ecology 87:334339.

Loxterman, J. L., and E. R. Keeley. 2012. Watershed boundaries and geographic isolation: Patterns of diversification in cutthroat trout from western North America. BMC Evolutionary Biology 12:38.

Ma, C., Y. Shen, D. Bearup, W. F. Fagan, and J. Liao. 2020. Spatial variation in branch size promotes metapopulation persistence in dendritic river networks. Freshwater Biology $65: 426-434$.

Magoulick, D. D., and R. M. Kobza. 2003. The role of refugia for fishes during drought: A review and synthesis. Freshwater Biology 48:1186-1198.

Manel, S., P. E. Guerin, D. Mouillot, S. Blanchet, L. Velez, C. Albouy, and L. Pellissier. 2020. Global determinants of freshwater and marine fish genetic diversity. Nature Communications 11:1-9.

Mari, L., R. Casagrandi, E. Bertuzzo, A. Rinaldo, and M. Gatto. 2014. Metapopulation persistence and species spread in river networks. Ecology Letters 17:426-434.

Marsh, P. C., and M. E. Douglas. 1997. Predation by introduced fishes on endangered humpback chub and other native species in the Little Colorado River, Arizona. Transactions of the American Fisheries Society 126:343-346. 
873

874

875

876

877

878

879

880

881

882

883

884

885

886

887

888

889

890

891

892

893

894

895

896

897

898

899

900

901

902

903

904

905

906

907

908

909

910

911

912

Martinez, A. S., J. R. Willoughby, and M. R. Christie. 2018. Genetic diversity in fishes is influenced by habitat type and life-history variation. Ecology and Evolution 8:1202212031.

McCluney, K. E., N. L. Poff, M. A. Palmer, J. H. Thorp, G. C. Poole, B. S. Williams, M. R. Williams, and J. S. Baron. 2014. Riverine macrosystems ecology: Sensitivity, resistance, and resilience of whole river basins with human alterations. Frontiers in Ecology and the Environment 12:48-58.

McKinney, G. J., R. K. Waples, L. W. Seeb, and J. E. Seeb. 2017. Paralogs are revealed by proportion of heterozygotes and deviations in read ratios in genotyping-by-sequencing data from natural populations. Molecular Ecology Resources, 17:656-669

McManamay, R. A., and E. A. Frimpong. 2015. Hydrologic filtering of fish life history strategies across the United States: Implications for stream flow alteration. Ecological Applications 25:243-263.

McManamay, R. A., M. J. Troia, C. R. DeRolph, A. O. Sheldon, A. R. Barnett, S. C. Kao, and M. G. Anderson. 2018. A stream classification system to explore the physical habitat diversity and anthropogenic impacts in riverscapes of the eastern United States. Page PLoS ONE.

McRae, B. H. 2006. Isolation by resistance. Evolution 60:1551.

McRae, B. H., and P. Beier. 2007. Circuit theory predicts gene flow in plant and animal populations. Proceedings of the National Academy of Sciences of the United States of America 104:19885-19890.

Mcrae, B., V. Shah, and A. Edelman. 2016. Circuitscape: modeling landscape connectivity to promote conservation and human health. The Nature Conservancy.

Meffe, G. K., and R. C. Vrijenhoek. 1988. Conservation genetics in the management of desert fishes. Conservation Biology 2:157-169.

Meirmans, P. G., and P. W. Hedrick. 2011. Assessing population structure: FST and related measures. Molecular Ecology Resources 11:5-18.

Meyers, P. J., and M. C. Belk. 2014. Shape variation in a benthic stream fish across flow regimes. Hydrobiologia 738:147-154.

Miller, R. R., J. D. Williams, and J. E. Williams. 1989. Extinctions of North American fishes during the past century. Fisheries 14:22-38.

Minckley, W. L., D. Hendrickson, and C. Bond 1986. Geography of western North American freshwater fishes: description and relationships to intracontinental tectonism. The Zoogeography of North American Freshwater Fishes:519-613.

Minckley, W. L., and J. E. Deacon. 1968. Southwestern fishes and the enigma of "endangered species." Science 159:1424-1432.

Minckley, W. L. 1973. Fishes of Arizona. Arizona Game and Fish Department, Phoenix, AZ.

Morrissey, M. B., and D. T. De Kerckhove. 2009. The maintenance of genetic variation due to asymmetric gene flow in dendritic metapopulations. American Naturalist 174:875-889.

Mussmann, S. M., M. R. Douglas, T. K. Chafin, and M. E. Douglas. 2020a. AdmixPipe: 
Population analyses in ADMIXTURE for non-model organisms. BMC Bioinformatics 21:337.

Mussmann, S. M., M. R. Douglas, D. D. Oakey, and M. E. Douglas. 2020b. Defining relictual biodiversity: Conservation units in speckled dace (Leuciscidae: Rhinichthys osculus) of the Greater Death Valley ecosystem. Ecology and Evolution 10:10798-10817.

Nadeau, T. L., and M. C. Rains. 2007. Hydrological connectivity of headwaters to downstream waters: Introduction to the featured collection. Journal of the American Water Resources Association 43:1-4.

Nielsen, E. S., M. Beger, R. Henriques, K. A. Selkoe, and S. von der Heyden. 2017. Multispecies genetic objectives in spatial conservation planning. Conservation Biology 31:872-882.

Nilsson, C., C. A. Reidy, M. Dynesius, and C. Revenga. 2005. Fragmentation and flow regulation of the world's large river systems. Science 308:405-408.

Oakey, D. D., M. E. Douglas, and M. R. Douglas. 2004. Small fish in a large landscape: Diversification of Rhinichthys osculus (Cyprinidae) in Western North America. Copeia 2004:207-221.

Orsini, L., J. Vanoverbeke, I. Swillen, J. Mergeay, and L. De Meester. 2013. Drivers of population genetic differentiation in the wild: Isolation by dispersal limitation, isolation by adaptation and isolation by colonization. Molecular Ecology 22:5983-5999.

Osborne, M. J., J. S. Perkin, K. B. Gido, and T. F. Turner. 2014. Comparative riverscape genetics reveals reservoirs of genetic diversity for conservation and restoration of Great Plains fishes. Molecular Ecology 23:5663-5679.

Paris, J. R., J. R. Stevens, and J. M. Catchen. 2017. Lost in parameter space: a road map for stacks. Methods in Ecology and Evolution, 8:1360-1373.

Paz-Vinas, I., and S. Blanchet. 2015. Dendritic connectivity shapes spatial patterns of genetic diversity: A simulation-based study. Journal of Evolutionary Biology 28:986-994.

Paz-Vinas, I., G. Loot, V. Hermoso, C. Veyssiere, N. Poulet, G. Grenouillet, and S. Blanchet. 2018. Systematic conservation planning for intraspecific genetic diversity. Proceedings of the Royal Society B: Biological Sciences 285:20172746.

Paz-Vinas, I., G. Loot, V. M. Stevens, and S. Blanchet. 2015. Evolutionary processes driving spatial patterns of intraspecific genetic diversity in river ecosystems. Molecular Ecology $24: 4586-4604$.

Peterman, W. E. 2018. ResistanceGA: An R package for the optimization of resistance surfaces using genetic algorithms. Methods in Ecology and Evolution 9:1638-1647.

Peterman, W. E., and N. S. Pope. 2020. The use and misuse of regression models in landscape genetic analyses. Molecular Ecology:1-11.

Peterman, W. E., K. J. Winiarski, C. E. Moore, C. da S. Carvalho, A. L. Gilbert, and S. F. Spear. 2019. A comparison of popular approaches to optimize landscape resistance surfaces. Landscape Ecology 34:2197-2208.

Peterson, E. E., J. M. Ver Hoef, D. J. Isaak, J. A. Falke, M. J. Fortin, C. E. Jordan, K. McNyset, P. Monestiez, A. S. Ruesch, A. Sengupta, N. Som, E. A. Steel, D. M. Theobald, C. E. 
992

Torgersen, and S. J. Wenger. 2013. Modelling dendritic ecological networks in space: An integrated network perspective. Ecology Letters 16:707-719.

Pfrender, M. E., J. Hicks, and M. Lynch. 2004. Biogeographic patterns and current distribution of molecular-genetic variation among populations of speckled dace, Rhinichthys osculus (Girard). Molecular Phylogenetics and Evolution 30:490-502.

Pilger, T. J., K. B. Gido, D. L. Propst, J. E. Whitney, and T. F. Turner. 2017. River network architecture, genetic effective size and distributional patterns predict differences in genetic structure across species in a dryland stream fish community. Molecular Ecology.

Pritchard, J. K., M. Stephens, and P. Donnelly. 2000. Inference of population structure using multilocus genotype data. Genetics 155:945-959.

Probst, D. L., K. B. Gido, and J. A. Stefferud. 2008. Natural flow regimes, nonnative fishes, and native fish persistence in arid-land river systems. Ecological Applications 18:1236-1252.

Propst, D. L., and K. B. Gido. 2004. Responses of native and nonnative fishes to natural flow regime mimicry in the San Juan River. Transactions of the American Fisheries Society 133:922-931.

Prügel-Bennett, A. 2004. When a genetic algorithm outperforms hill-climbing. Theoretical Computer Science 320:135-153.

Prunier, J. G., V. Dubut, G. Loot, L. Tudesque, and S. Blanchet. 2018. The relative contribution of river network structure and anthropogenic stressors to spatial patterns of genetic diversity in two freshwater fishes: A multiple-stressors approach. Freshwater Biology 63:6-21.

Rabosky, D. L. 2020. Speciation rate and the diversity of fishes in freshwaters and the oceans. Journal of Biogeography 47:1207-1217.

Raffard, A., F. Santoul, S. Blanchet, and J. Cucherousset. 2020. Linking intraspecific variability in trophic and functional niches along an environmental gradient. Freshwater Biology 65:1401-1411.

Rochette, N. C., A. G. Rivera-Colón, and J. M. Catchen. 2019. Stacks 2: Analytical methods for paired-end sequencing improve RADseq-based population genomics. Molecular Ecology 28:4737-4754

Rodríguez-González, P. M., C. García, A. Albuquerque, T. Monteiro-Henriques, C. Faria, J. B. Guimarães, D. Mendonça, F. Simões, M. T. Ferreira, A. Mendes, J. Matos, and M. H. Almeida. 2019. A spatial stream-network approach assists in managing the remnant genetic diversity of riparian forests. Scientific Reports 9:1-10.

Rolls, R. J., J. Heino, and B. C. Chessman. 2016. Unravelling the joint effects of flow regime, climatic variability and dispersal mode on beta diversity of riverine communities. Freshwater Biology 61:1350-1364.

Rousset, F. 1997. Genetic differentiation and estimation of gene flow from F-statistics under isolation by distance. Genetics 145:1219-1228.

Ruhí, A., E. E. Holmes, J. N. Rinne, and J. L. Sabo. 2015. Anomalous droughts, not invasion, decrease persistence of native fishes in a desert river. Global Change Biology 21:14821496. 
993

994

995

996

997

998

999

1000

1001

1002

1003

1004

1005

1006

1007

1008

1009

1010

1011

1012

1013

1014

1015

1016

1017

1018

1019

1020

1021

1022

1023

1024

1025

1026

1027

1028

1029

1030

1031

1032

Schlosser, I. J. 1995. Critical landscape attributes that influence fish population dynamics in headwater streams. Hydrobiologia 303:71-81.

Seegert, S. E. Z., E. J. Rosi-Marshall, C. V. Baxter, T. A. Kennedy, R. O. Hall, and W. F. Cross. 2014. High diet overlap between native small-bodied fishes and nonnative fathead minnow in the Colorado River, Grand Canyon, Arizona. Transactions of the American Fisheries Society 143:1072-1083.

Seymour, M., E. A. Fronhofer, and F. Altermatt. 2015. Dendritic network structure and dispersal affect temporal dynamics of diversity and species persistence. Oikos 124:908-916.

Shah, V. B., and B. H. McRae. 2008. Circuitscape: A tool for landscape ecology. Proceedings of the 7th Python in Science Conference.

Shen, Y., Z. Xu, I. Nijs, and J. Liao. 2018. Spatial arrangement of size-different patches determines population dynamics in linear riverine systems. Ecological Modelling 385:220225.

Singhal, S., H. Huang, M. R. Grundler, M. R. Marchán-Rivadeneira, I. Holmes, P. O. Title, S. C. Donnellan, and D. L. Rabosky. 2018. Does population structure predict the rate of speciation? A comparative test across Australia's most diverse vertebrate radiation. The American Naturalist 192:432-447.

Smith, G. R., and T. E. Dowling. 2008. Correlating hydrographic events and divergence times of speckled dace (Rhinichthys: Teleostei: Cyprinidae) in the Colorado River drainage. Geological Society of America Special Papers 439:301-317.

Smouse, P. E., J. C. Long, and R. R. Sokal. 1986. Multiple regression and correlation extensions of the Mantel test of matrix correspondence. Systematic Zoology 35:627.

Spear, S. F., N. Balkenhol, M. J. Fortin, B. H. McRae, and K. Scribner. 2010. Use of resistance surfaces for landscape genetic studies: Considerations for parameterization and analysis. Molecular Ecology 19:3576-3591.

Tamura, K., and M. Nei. 1993. Estimation of the number of nucleotide substitutions in the control region of mitochondrial DNA in humans and chimpanzees. Molecular Biology and Evolution 10:512-526.

Tang, Q., T. Fung, and F. E. Rheindt. 2020. ResDisMapper: An R package for fine-scale mapping of resistance to dispersal. Molecular Ecology Resources 20:819-831.

Terui, A., N. Ishiyama, and H. Urabe. 2019. Metapopulation stability in branching river network. Proceedings of the National Academy of Sciences of the United States of America 115:E5963-E5969.

Thomaz, A. T., M. R. Christie, and L. L. Knowles. 2016. The architecture of river networks can drive the evolutionary dynamics of aquatic populations. Evolution 70:731-739.

Troia, M. J., A. L. Kaz, J. C. Niemeyer, and X. Giam. 2019. Species traits and reduced habitat suitability limit efficacy of climate change refugia in streams. Nature Ecology and Evolution 3:1321-1330.

Troia, M. J., and R. A. McManamay. 2020. Biogeographic classification of streams using fish community- and trait-environment relationships. Diversity and Distributions 26:108-125. 
1033 Walker, A. E., J. N. Moore, P. E. Grams, D. J. Dean, and J. C. Schmidt. 2020. Channel narrowing by inset floodplain formation of the lower Green River in the Canyonlands region, Utah. GSA Bulletin 132:2333-2352.

1036 Weir, B., and C. C. Cockerham. 1984. Estimating F-Statistics for the analysis of population 1037 structure. Evolution 38:1358-1370.

1038 White, S. L., E. M. Hanks, and T. Wagner. 2020. A novel quantitative framework for riverscape 1039 genetics. Ecological Applications 30:1-17.

1040 Whitney, J. E., J. B. Whittier, and C. P. Paukert. 2017. Environmental niche models for riverine desert fishes and their similarity according to phylogeny and functionality. Ecosphere

1043 Winiarski, K. J., W. E. Peterman, and K. McGarigal. 2020. Evaluation of the R package 'ResistanceGA': A promising approach towards the accurate optimization of landscape resistance surfaces. Molecular Ecology Resources 20:1583-1596.

1046 Zeller, K. A., K. McGarigal, and A. R. Whiteley. 2012. Estimating landscape resistance to movement: A review. Landscape Ecology 27:777-797. 


\section{Figures and Tables}

1051 Table 1: Description of environmental variables used as covariates in multiple tests of riverscape genetic differentiation in Speckled Dace (Rhinichthys osculus) in the Colorado River Basin,

1053 where "FFR" refers to the dataset of Grill et al. (2019)

1054

\begin{tabular}{lll}
\hline Variable & Description & Source \\
\hline AET & Actual evapotranspiration (from soil water deficit); & RiverATLAS \\
& equivalent to 'soil water stress coefficient' & \\
ARI & Aridity index & RiverATLAS \\
CRP & Cropland extent as percentage of reach catchment & RiverATLAS \\
CSI & Connectivity status index & FFR \\
DOF & $\begin{array}{l}\text { Degree/ index of fragmentation due to artificial and/ or } \\
\text { natural barriers }\end{array}$ & FFR \\
& & \\
DOR & Degree/ index of anthropogenic flow regulation & FFR \\
FLD & Floodplain extent, as percentage of reach catchment & FFR \\
FOR & Forest landcover percentage in reach catchment & RiverATLAS \\
HFT & Standardized human footprint index & RiverATLAS \\
HDI & Human development index & RiverATLAS \\
KAR & Percentage of catchment exposed karst terrain & RiverATLAS \\
PAC & Percentage of reach catchment in protected areas & RiverATLAS \\
PET & Potential evapotranspiration predicted from WorldClim & RiverATLAS \\
POP & Scaled human population size in 2010 & RiverATLAS \\
PST & Pasture extent as percentage of reach catchment & RiverATLAS \\
RDD & Road crossing density & FFR \\
RIV & River volume along reach segment & RiverATLAS \\
REV & Reservoir volume in watershed upstream of reach & RiverATLAS \\
RUN & Annual average land surface discharge and runoff & RiverATLAS \\
SGR & Stream gradient; ratio of elevation differential in reach & RiverATLAS \\
& and reach length & \\
SLP & Average slope degree in catchment & RiverATLAS \\
SOC & Soil organic carbon content & HydroATLAS \\
TMP & Mean annual temperature & RiverATLAS \\
URB & Percentage catchment area classified as urban & RiverATLAS \\
USE & Proportion of water removed for human use & FFR \\
\hline & & \\
\hline
\end{tabular}


1057

1058

1059

1060

1061

1062

1063

1064

1065
Table 2: Relative importance of variables (=Variable) involved with multiple methods for testing environmental association versus genetic differentiation in Speckled Dace (Rhinichthys osculus) from the Colorado River Basin. Values for generalized linear modeling (=GLMULTI) represent the sum of Akaike weights for models fit, using edge-wise means $\left(=\mathrm{RVI}_{\mu}\right)$, calculated from all reaches comprising a given stream segment, and of edge-wise variation coefficients ( $\left.=\mathrm{RVI}_{c v}\right)$. Results for partial redundancy analyses $(=\mathrm{pRDA})$ represent $R^{2}$ values expressed as percentage (x100), from analyses of edge-wise means $\left(=R^{2}{ }_{\mu}\right)$ and variation coefficients $\left(=R_{c v}^{2}\right)$. Model-averaged weights $\left(=\mathrm{W}_{R e p N}\right)$ for each variable are presented as a component of composite resistance models fitted in RESISTNET across four replicates, where Akaike weights are computed using a maximum-likelihood population effects mixed model. Variables not meeting a RVI threshold of 0.8 (GLMULTI and RESISTNET) or not chosen using a forward-selection procedure (pRDA) are represented with a hyphen (-).

\begin{tabular}{|c|c|c|c|c|c|c|c|c|}
\hline \multirow[b]{2}{*}{ Variable } & \multicolumn{2}{|c|}{ GLMULTI } & \multicolumn{2}{|c|}{ PRDA } & \multicolumn{3}{|c|}{ RESISTNET } & \multirow[b]{2}{*}{$\mathrm{W}_{\operatorname{Rep} 4}$} \\
\hline & $\mathrm{RVI}_{\mu}$ & $\mathrm{RVI}_{c v}$ & $R_{\mu}^{2}(\mathrm{x} 100)$ & $R_{c v}^{2}(\mathrm{x} 100)$ & $\mathrm{W}_{\text {Repl }}$ & $\mathrm{W}_{\text {Rep } 2}$ & $\mathrm{~W}_{\operatorname{Rep} 3}$ & \\
\hline AET & - & - & $3.9 \%$ & - & 0.94 & - & 0.55 & - \\
\hline ARI & - & 0.990 & $2.9 \%$ & - & 0.38 & 0.63 & 0.30 & 0.56 \\
\hline CRP & - & - & - & - & 0.60 & 0.65 & 0.72 & 0.45 \\
\hline CSI & 0.992 & - & - & $2.2 \%$ & - & - & 0.51 & 0.49 \\
\hline DOF & 0.971 & - & $1.5 \%$ & - & 0.32 & - & - & - \\
\hline DOR & - & 0.998 & $1.7 \%$ & - & 0.53 & 0.63 & 0.60 & 0.59 \\
\hline FOR & - & - & - & - & - & - & - & - \\
\hline FLD & - & 0.999 & - & - & - & - & - & - \\
\hline HDI & 0.999 & - & - & - & - & - & - & - \\
\hline HFT & - & - & - & - & 0.62 & 0.58 & 0.93 & 0.56 \\
\hline KAR & - & - & - & - & - & - & - & - \\
\hline LENGTH & - & - & - & - & - & - & - & - \\
\hline PAC & 0.992 & - & - & - & 0.70 & 0.25 & 0.35 & 0.24 \\
\hline PET & - & - & - & $4.3 \%$ & 0.66 & 0.55 & 0.79 & 0.53 \\
\hline POP & 0.993 & - & - & - & 0.35 & - & - & 0.15 \\
\hline PST & - & - & - & - & - & - & - & 0.08 \\
\hline RDD & - & - & - & - & 0.42 & - & - & - \\
\hline REV & 0.992 & 0.930 & - & - & - & - & - & - \\
\hline RIV & - & - & - & - & - & - & - & - \\
\hline RUN & - & - & - & - & - & - & - & - \\
\hline SED & - & - & - & - & 0.45 & 0.75 & 0.77 & 0.75 \\
\hline SGR & - & - & - & - & - & 0.10 & 0.06 & - \\
\hline SLP & - & - & - & $1.8 \%$ & 0.36 & - & - & 0.29 \\
\hline $\mathrm{SOC}$ & - & 0.999 & - & $3.3 \%$ & 0.28 & 0.41 & - & 0.40 \\
\hline TMP & 0.990 & 0.956 & - & - & - & - & - & - \\
\hline URB & - & - & - & - & - & 0.16 & 0.08 & 0.24 \\
\hline USE & 0.999 & 0.830 & $2.2 \%$ & - & 0.72 & 0.51 & 0.43 & 0.52 \\
\hline
\end{tabular}


Figure 1: Workflows summarized for DisTNET and RESISTNET. DisTNET reduces an input shapefile to a minimal graph, using Dijkstra shortest paths between points, and merging contiguous reaches to form edges. Input genetic distances are 'fitted' to the graph using a least-squares procedure, and results are annotated against the original geometries. RESISTNET optimizes resistance models using a genetic algorithm, where a population of random models is 'evolved' given a fitness function (e.g., AIC), which is computed by comparing the effective resistances computed on the graph for each model (using CIRCUITSCAPE) against either an input pairwise genetic distance matrix, or edge-wise fitted distances from DISTNET . For each generation, models are mutated (=random parameter changes), recombined (=swapping parameter sets), selected (=included/ excluded on the basis of a fitness function), and used to generate offspring for the succeeding generation. Final results are used to compute an effective resistance network and relative variable importance values using model-averaging.
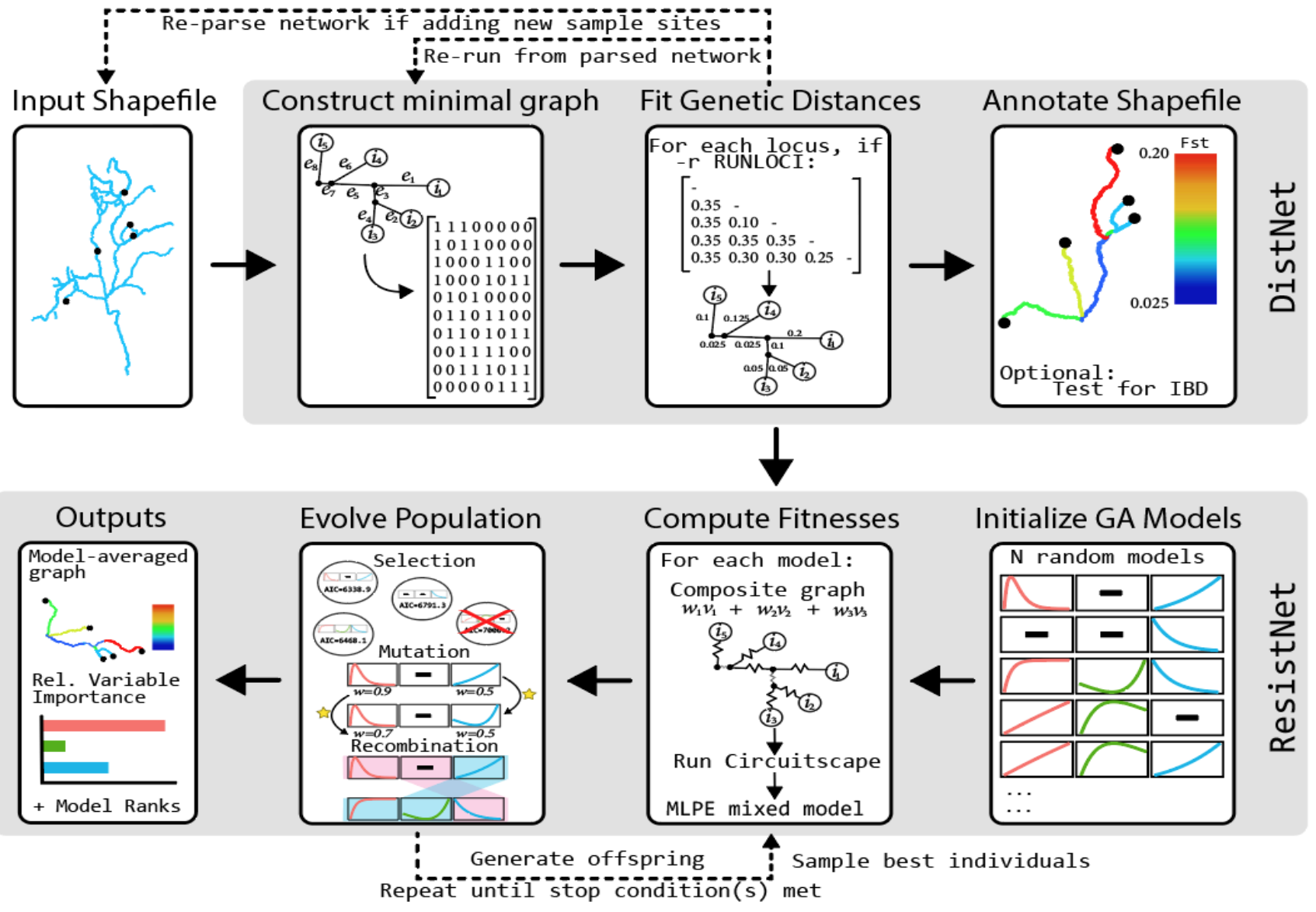
Figure 2: Distribution of $N=78$ Speckled Dace (Rhinichthys osculus) sample localities in the Colorado River Basin, as divided into five sub-basins: Virgin River; Grand Canyon; Little Colorado River (=Little CR); Upper Colorado River Basin (=Upper CR); and Gila+Bill Williams

1080 rivers (=Gila). Sample sites color-coded per resident sub-basin.

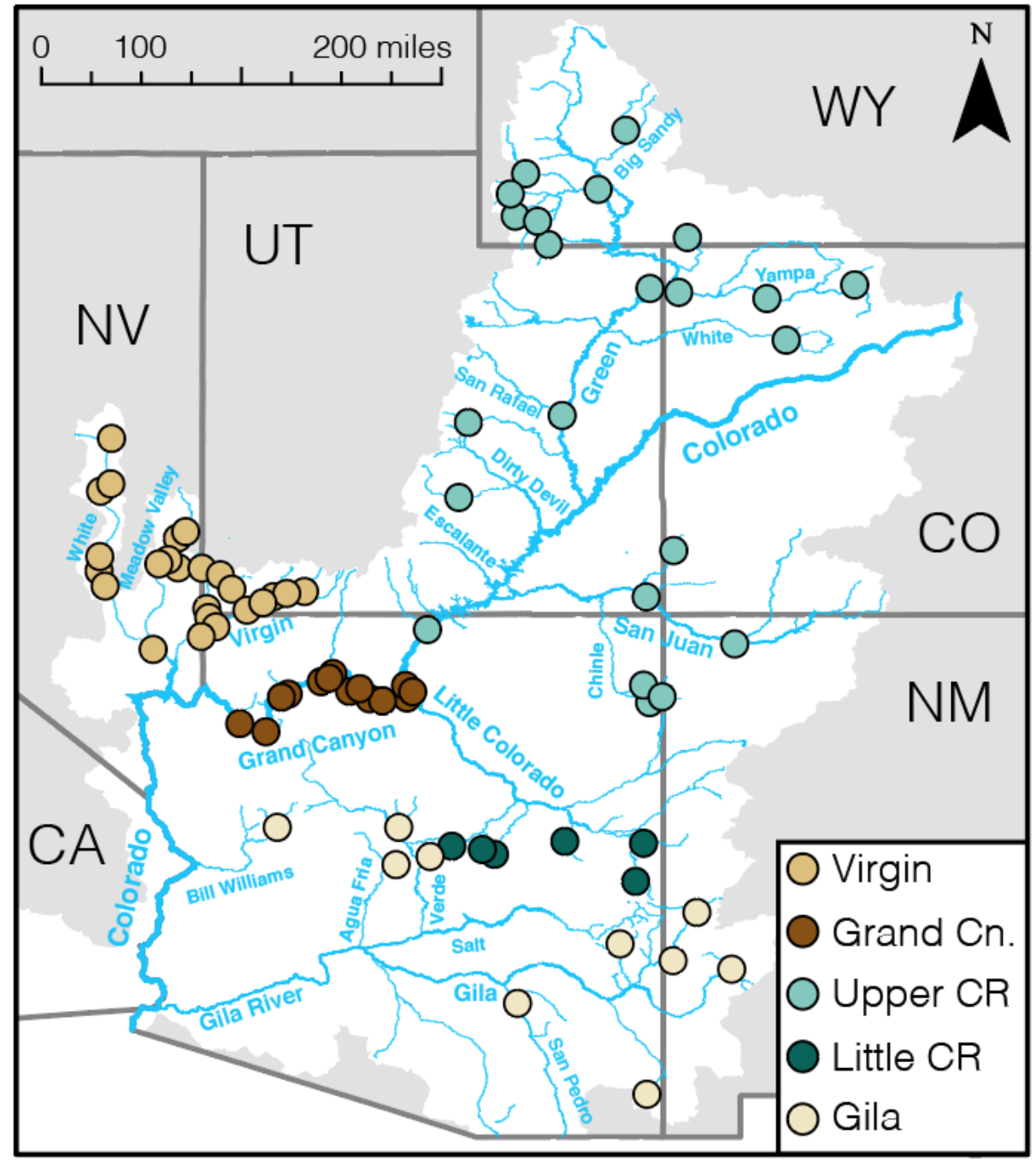


Figure 3: Population structure among Colorado River Basin (CRB) Speckled Dace populations. Upper Colorado/ Green River aggregates $(K=6)$ represent: Paria River (PAR), Chinle Wash (CYC-WHY), San Juan+San Rafael+Fremont rivers (DOL-FER), Lower-Mid Green River (DES-BIG), Smiths Fork (SMF), and Vermillion Creek (NVC). The Lower CRB, represented by the Gila+Bill Williams River drainages $(K=8)$ include: the Bill Williams River (FRA), Verde River (FOS-SPG), Agua Fria (SYC), San Pedro (ARU), San Simon (NCC), Eagle Creek (EAG), San Francisco River (GLN-TUL), and Upper Gila River (WFG). The Little Colorado River $(K=4)$ encompasses East Clear Creek (WIL-ECC), Chevelon Creek (CHE), Silver Creek (SIC), and the East Fork (WEN-EFL). Grand Canyon ( $K=5)$ : distributed linearly along the length of the canyon, with the exception of Havasu Creek (HAV). Virgin River $(K=7)$ : upper Virgin River (NTH-NFV), Mainstem Virgin River (LAV-WFA; BDW-VSC), Beaver Dam Wash (BDMCCN), Meadow Valley Wash (BBL-MVW), Moapa River (MOA), Pahranagat (PAH-VEL), and White River (ISP-CAM).

Green River/ Upper Colorado
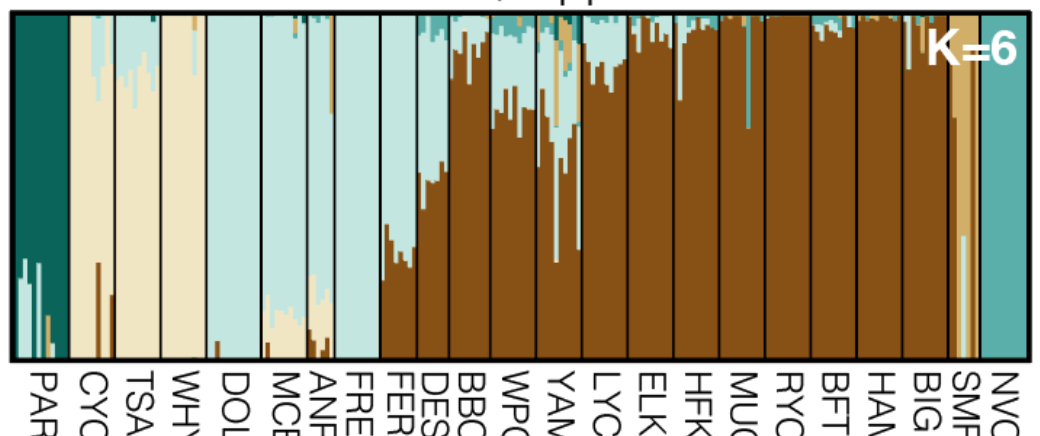

Grand Canyon

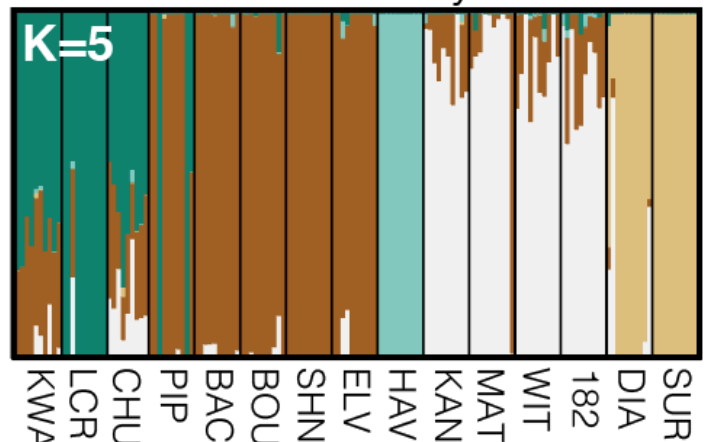

Gila/ Bill Williams

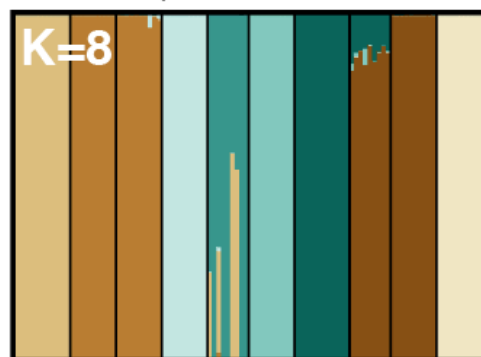

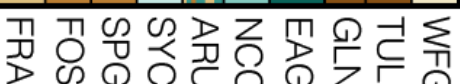
Virgin River

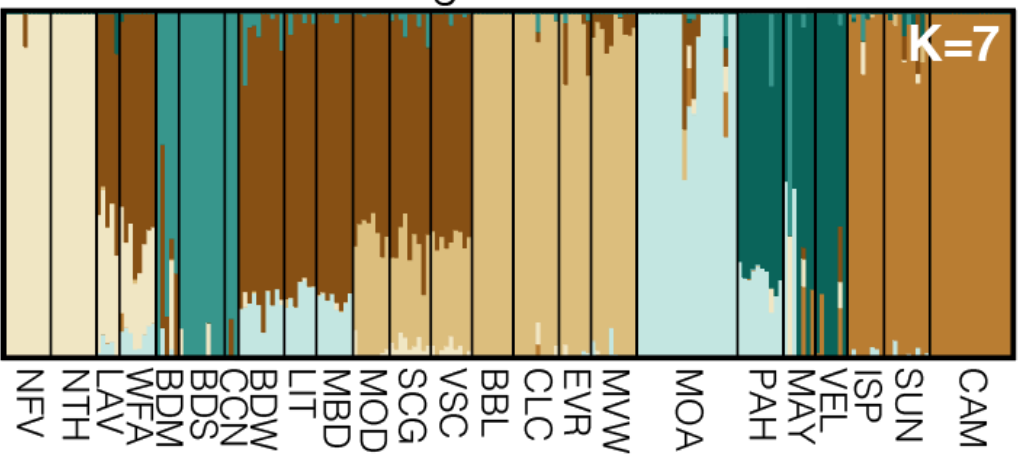


1095

1096

1097

1098

1099

1100

1101

1102

1103

Figure 4: Composite plot of DiSTNET results for $N=78$ Speckled Dace (Rhinichthys osculus) sampling localities distributed throughout the Colorado River Basin. (A) Linearized $F_{\mathrm{ST}}\left(F_{\mathrm{ST}} / 1\right.$ $\left.F_{\mathrm{ST}}\right)$ computed globally across loci, fitted to stream edges; $(\mathrm{B})$ Mean fitted $F_{\mathrm{ST}}$ estimates computed across 13,218 SNP loci; (C) Standard deviation (Std. Dev.) of per-locus fitted $F_{\mathrm{ST}}$ estimates; (D) Histogram of 'snap' distances between true sampling localities and nearest river network node; (E) Globally computed, linearized $F_{\text {ST }}$ versus those predicted from DISTNET fitted values (linear regression: adjusted $\left.R^{2}=0.77, p<1.0 e^{-16}\right)$; (F) Pairwise stream distances among sites versus pairwise linearized $F_{\mathrm{ST}}$ (Mantel $r=0.47, p<0.001$ ).
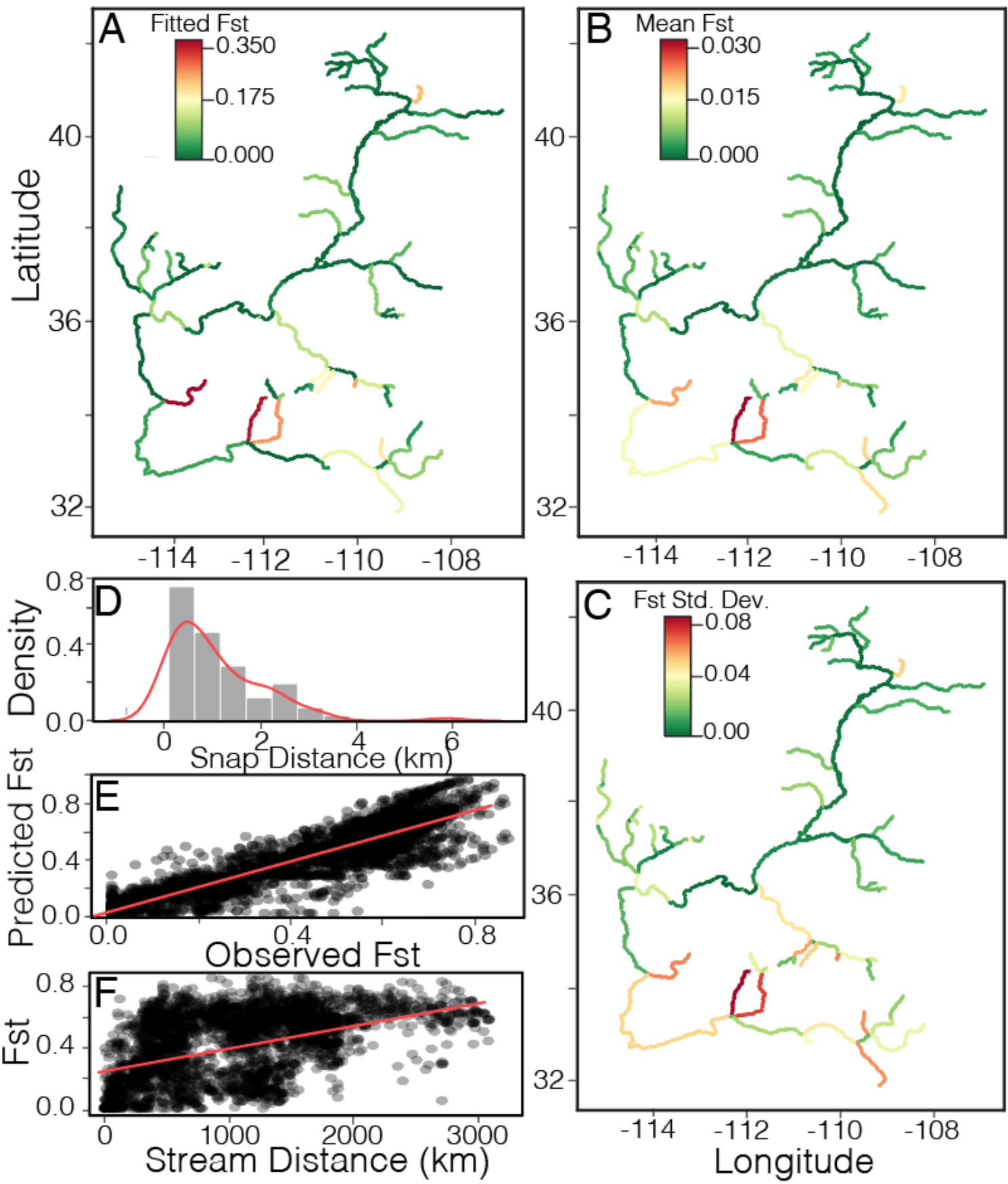
Figure 5: Modelling association of 27 environmental values and stream length with fitted- $F_{\text {ST }}$ values for 113 contiguous stream segments (=network edges) in the Colorado River Basin, as inferred using $N=78$ sampling localities of Speckled Dace (Rhinichthys osculus) and 13,218 SNP loci and least-squares optimization in DiSTNET. (A) model-averaged relative variable importance (RVI) for generalized linear models (GLMs) fit using mean $F_{\mathrm{ST}}$ across loci per edge $\left(\mathrm{RVI}_{\mu}\right)$ and using variation coefficients $\left(\mathrm{RVI} \mathrm{I}_{c v}\right)$, with a RVI threshold of 0.8 (red line); (B-C) Partial redundancy analyses (pRDA controlled for stream length) of locus-wise $F_{\text {ST }}$ means across edges, scaled by loci; (D-E) pRDA of locus-wise $F_{\text {ST }}$ means, scaled by edge; and pRDA of locus-wise $F_{\text {ST }}$ variation coefficients,

1111 scaled by loci (F-G), and by edge (H-I). pRDA variables chosen via forward selection. Variable abbreviations (e.g., AET) per Table 1.

1112
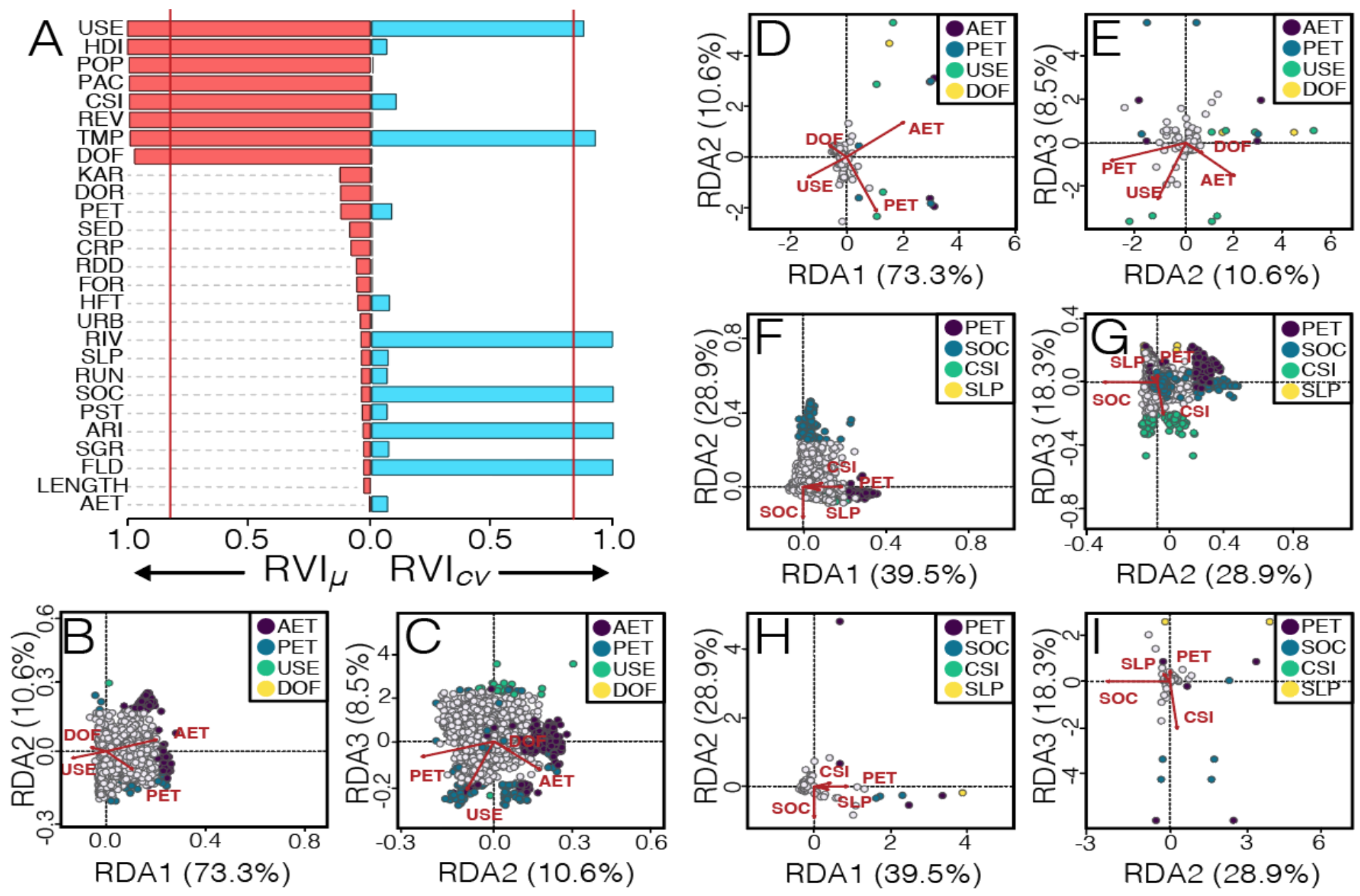
1114

1115

1116

1117

1118

1119

1120
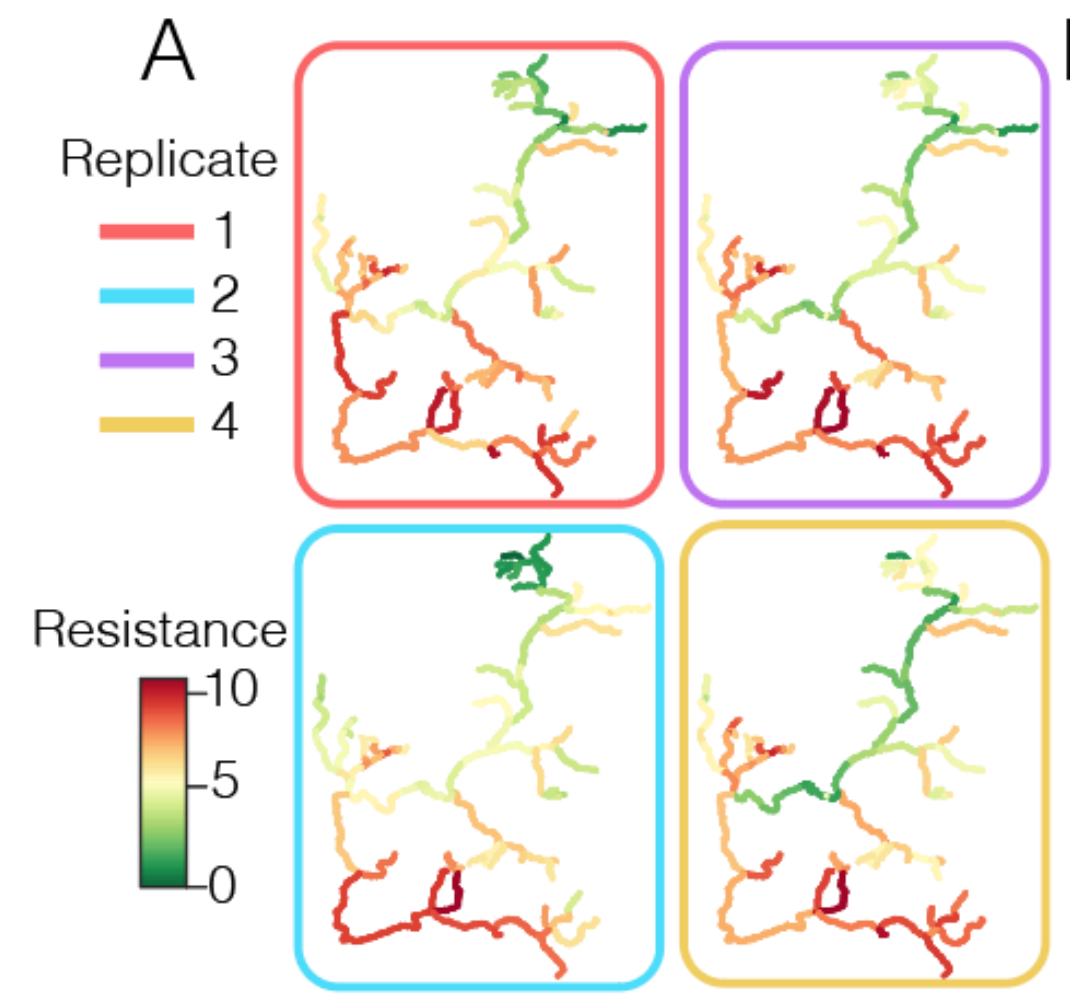
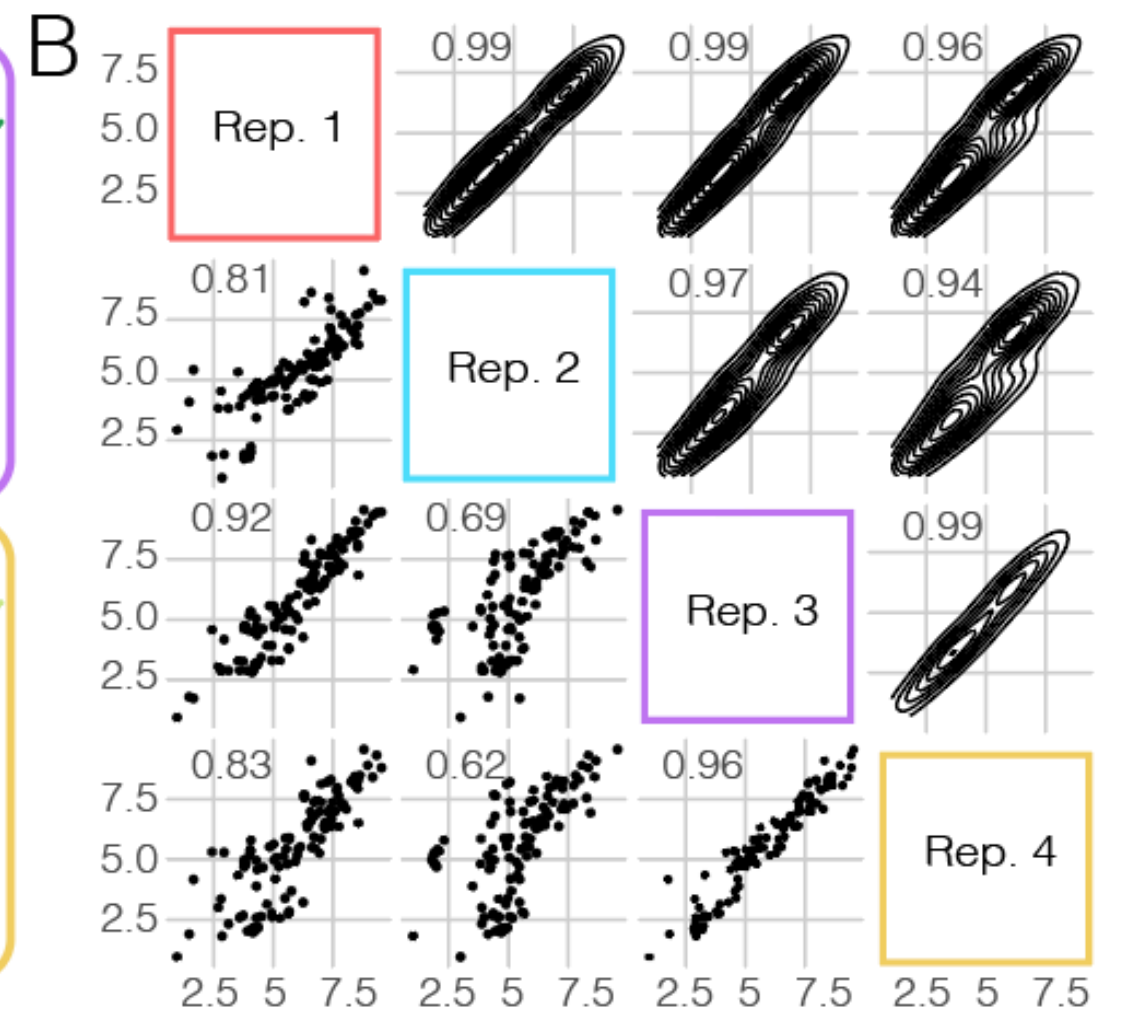

Rep. 4

57.5

1121 


\section{Supplementary Material}

1123 Table S1: Locality information (=Locality) and sample sizes $(=\mathrm{N})$ for $N=78$ sampling localities

1124 of Speckled Dace (Rhinichthys osculus) in sub-basins (=Sub-Basin) of the Colorado River Basin.

1125

\begin{tabular}{|c|c|c|c|}
\hline Site & Locality & Sub-basin & $N$ \\
\hline 182 & Grand Canyon RM182 & Grand Canyon & 10 \\
\hline ANR & Animas River & Upper CRB & 6 \\
\hline ARU & Aravaipa Creek; San Pedro tributary & Lower CRB & 12 \\
\hline BAC & Grand Canyon RM87-117 & Grand Canyon & 10 \\
\hline $\mathrm{BBC}$ & Big Beaver Creek - White River & Upper CRB & 9 \\
\hline BBL & Meadow Valley Wash & Virgin & 9 \\
\hline BDM & Beaver Dam Wash & Virgin & 6 \\
\hline BDS & Beaver Dam Wash & Virgin & 10 \\
\hline BDW & Mainstem Virgin River & Virgin & 10 \\
\hline BFT & Blacks Fork & Upper CRB & 10 \\
\hline $\mathrm{BIG}$ & Big Sandy River & Upper CRB & 10 \\
\hline $\mathrm{BOU}$ & Grand Canyon RM87-117 & Grand Canyon & 10 \\
\hline CAM & Camp Spring - White River & Virgin & 18 \\
\hline $\mathrm{CCN}$ & Beaver Dam Wash & Virgin & 4 \\
\hline $\mathrm{CHE}$ & Chevelon Creek; Little Colorado trib. & Little Colorado & 12 \\
\hline $\mathrm{CHU}$ & Grand Canyon RM225-249 & Grand Canyon & 9 \\
\hline CLC & Meadow Valley Wash & Virgin & 10 \\
\hline CYC & Chinle Wash; Colorado R. tributary & Upper CRB & 10 \\
\hline DES & Desolation Canyon; Green R. mainstem & Upper CRB & 7 \\
\hline DIA & Grand Canyon RM225-249 & Grand Canyon & 10 \\
\hline DOL & Dolores River & Upper CRB & 12 \\
\hline EAG & Eagle Creek & Lower CRB & 12 \\
\hline ECC & East Clear Creek; Little Colorado trib & Little Colorado & 12 \\
\hline EFL & East Fork, Little Colorado River & Little Colorado & 10 \\
\hline ELK & Elk River (Yampa River Tributary) & Upper CRB & 10 \\
\hline ELV & Grand Canyon RM87-117 & Grand Canyon & 10 \\
\hline EVR & Meadow Valley Wash & Virgin & 7 \\
\hline FER & Ferron Creek - San Rafael River & Upper CRB & 8 \\
\hline FOS & Fossil Creek; Verde River tributary & Lower CRB & 10 \\
\hline FRA & Francis Creek; Bill Williams R. tributary & Lower CRB & 12 \\
\hline FRE & Fremont River; Green River tributary & Upper CRB & 10 \\
\hline GLN & San Francisco River at Glenwood & Lower CRB & 9 \\
\hline HAM & Ham’s Fork; Green River & Upper CRB & 10 \\
\hline HAV & Havasu Creek, Grand Canyon & Grand Canyon & 10 \\
\hline HFK & Ham's Fork; Green River & Upper CRB & 10 \\
\hline ISP & Indian Springs; White River; Virgin-Muddy tributary & Virgin & 8 \\
\hline KAN & Kanab Creek; Grand Canyon & Grand Canyon & 10 \\
\hline KWA & Grand Canyon RM225-249 & Grand Canyon & 10 \\
\hline LAV & Mainstem Virgin River & Virgin & 5 \\
\hline
\end{tabular}




\begin{tabular}{|c|c|c|c|}
\hline LCR & Little Colorado River confluence & Grand Canyon & 10 \\
\hline LIT & Mainstem Virgin River & Virgin & 7 \\
\hline LYC & Little Yampa Canyon; Yampa River & Upper CRB & 10 \\
\hline MAT & Grand Canyon RM143-189 & Grand Canyon & 10 \\
\hline MAY & Maynard Spring - Pahranagat Valley & Virgin & 7 \\
\hline MBD & Mainstem Virgin River & Virgin & 8 \\
\hline MCE & McElmo Creek - San Juan River & Upper CRB & 10 \\
\hline MOA & Moapa River; Virgin-Muddy tributary & Virgin & 22 \\
\hline MOD & Mainstem Virgin River & Virgin & 8 \\
\hline MVW & Meadow Valley Wash & Virgin & 10 \\
\hline MUC & Muddy Creek - Blacks Fork River & Upper CRB & 10 \\
\hline $\mathrm{NCC}$ & San Simon & Lower CRB & 10 \\
\hline NFV & Upper Virgin River & Virgin & 10 \\
\hline NTH & Upper Virgin River & Virgin & 10 \\
\hline NVC & Vermillion Creek & Upper CRB & 10 \\
\hline PAH & Pahranagat River; Virgin-Muddy basin & Virgin & 10 \\
\hline PAR & Paria River & Upper CRB & 12 \\
\hline PIP & Grand Canyon RM87-117 & Grand Canyon & 10 \\
\hline $\mathrm{RYC}$ & Ryckman Creek upstream of Hill Creek Confluence & Upper CRB & 10 \\
\hline SCG & Mainstem Virgin River & Virgin & 9 \\
\hline $\mathrm{SIC}$ & Silver Creek; Little Colorado tributary & Little Colorado & 10 \\
\hline SHN & Shinumo Creek; Colorado R. tributary & Grand Canyon & 10 \\
\hline SMF & Smith's Fork; Green River & Upper CRB & 7 \\
\hline SPG & Spring Creek; Verde River tributary & Lower CRB & 10 \\
\hline SUN & Sunnyside Creek; White River; Virgin-Muddy & Virgin & 10 \\
\hline SUR & Grand Canyon RM225-249 & Grand Canyon & 10 \\
\hline SYC & Sycamore Creek; Agua Fria tributary & Lower CRB & 10 \\
\hline TSA & Chinle Wash; Colorado R. tributary & Upper CRB & 10 \\
\hline TUL & Tularosa Creek - San Francisco River & Lower CRB & 10 \\
\hline VEL & Burn's Ranch - Pahranagat Valley & Virgin & 7 \\
\hline VSC & Mainstem Virgin River & Virgin & 10 \\
\hline WEN & East Fork, Little Colorado R. & Little Colorado & 10 \\
\hline WFA & Mainstem Virgin River & Virgin & 8 \\
\hline WFG & West Fork of the Gila River at cliff dwellings & Lower CRB & 10 \\
\hline WIL & East Clear Creek; Little Colorado trib & Little Colorado & 10 \\
\hline WIT & Grand Canyon RM143-189 & Grand Canyon & 10 \\
\hline WPC & Island Park below Whirlpool Canyon; Yampa River & Upper CRB & 10 \\
\hline WHY & Chinle Wash; Colorado R. tributary & Upper CRB & 10 \\
\hline YAM & Yampa River (Green R. tributary) & Upper CRB & 10 \\
\hline
\end{tabular}


1127 Table S2: Outlier SNPs/ edges in pRDA analysis of means $(\mu)$ and variation coefficients $\left(c_{v}\right)$. 1128

1129

1130

\begin{tabular}{lcc}
\hline \multicolumn{1}{c}{ Variable } & $N$ SNPs (\%) & $N$ Edges (\%) \\
\hline$c_{v}-$ CSI & $105(30.1)$ & - \\
$c_{v}-$ PET & $112(32.1)$ & $3(42.9)$ \\
$c_{v}-$ SLP & $2(0.6)$ & $1(14.3)$ \\
$c_{v}-$ SOC & $130(37.2)$ & $3(42.9)$ \\
$\mu-$ AET & $158(71.5)$ & $2(22.2)$ \\
$\mu-$ DOF & - & $1(11.1)$ \\
$\mu-$ PET & $11(5.0)$ & $4(44.4)$ \\
$\mu-$ USE & $52(23.5)$ & $2(22.2)$ \\
\hline
\end{tabular}


1131 Table S3: Fitness metrics for the 'best' model selected in each of four independent RESISTNET

1132 replicate runs. Values represent: Log-likelihood ( $=\log l i k)$, AIC values, marginal $R^{2}$ of MLPE

1133 mixed model fit $\left(=R^{2} \mathrm{~m}\right)$, and change in likelihood as compared to the null model ( $\left.=\triangle A I C_{\text {null }}\right)$.

1134

\begin{tabular}{lllll}
\hline Replicate & $\log l i k$ & $A I C$ & $R_{\mathrm{m}}^{2}$ & $\Delta A I C_{\text {null }}$ \\
\hline 1 & -3087.17 & 6182.35 & 0.337 & 1151.52 \\
2 & -2991.06 & 5990.13 & 0.343 & 1201.49 \\
3 & -3086.74 & 6181.49 & 0.296 & 1006.52 \\
4 & -3053.56 & 6115.12 & 0.332 & 1141.73 \\
\hline
\end{tabular}


bioRxiv preprint doi: https://doi.org/10.1101/2021.03.25,437078; this version posted March 26, 2021. The copyright holder for this preprint (which was not certified by peer review) is the author/funder, who has granted bioRxiv a license to display the preprint in perpetuity. It is made available under aCC-BY-NC-ND 4.0 International license.

1136 Figure S1: Shapes of transformations used in RESISTNET at several shape parameter values $(1,3$ ,5, 10, 20, 50, 100). Transformed values maintain the scale of the input data (with a maximum of 10.0 and minimum of 0.0 ), and approach linearity as the shape parameter increases.

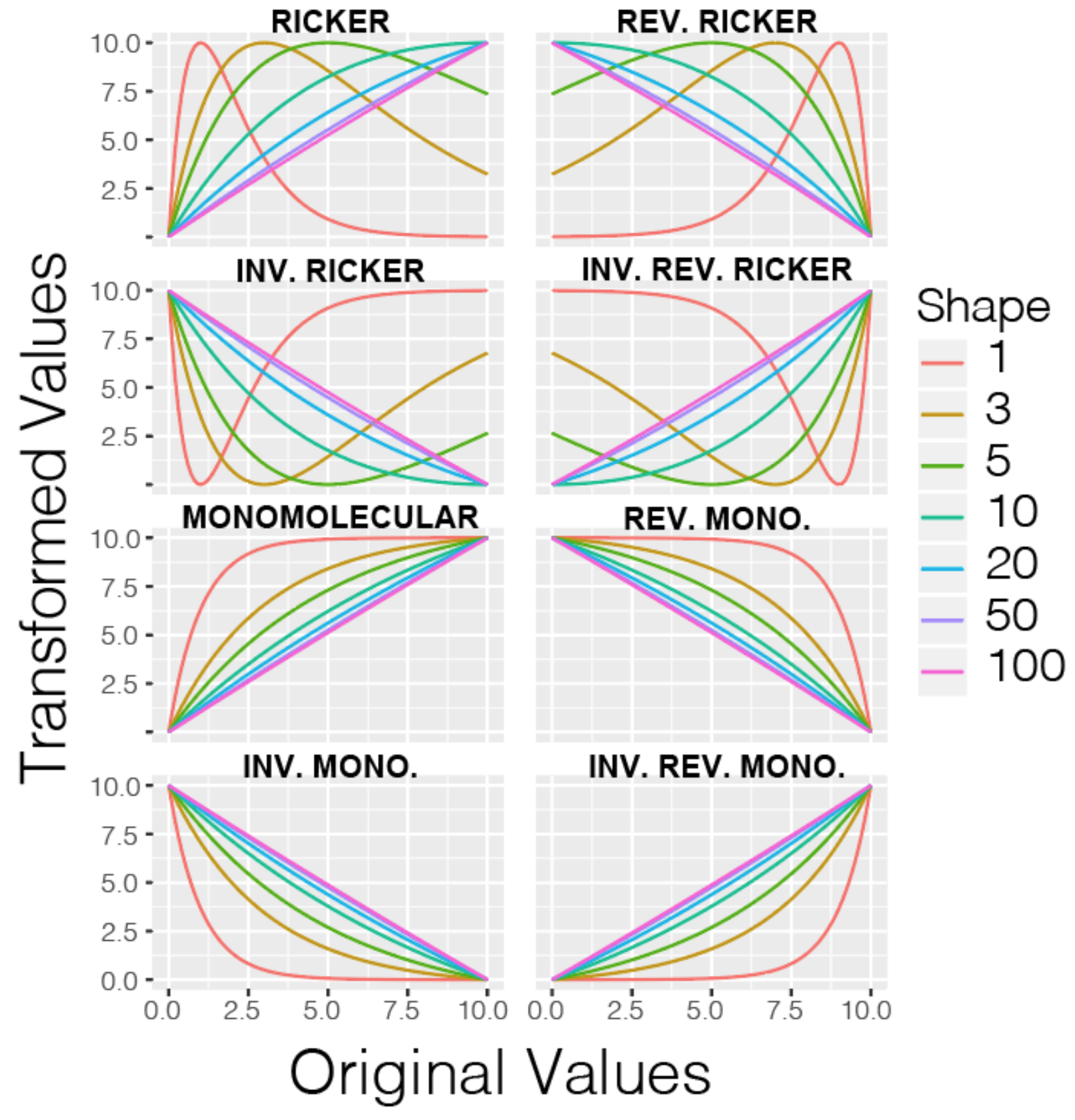


1141 Figure S2: Graph representation of the minimized stream network for Speckled Dace

1142 (Rhinichthys osculus) sampling sites $(\mathrm{N}=78)$ in the Colorado River Basin, with sample site (blue)

1143 and junction nodes (black) represented as circles, and stream segments (edges) as connecting

1144 lines.

1145

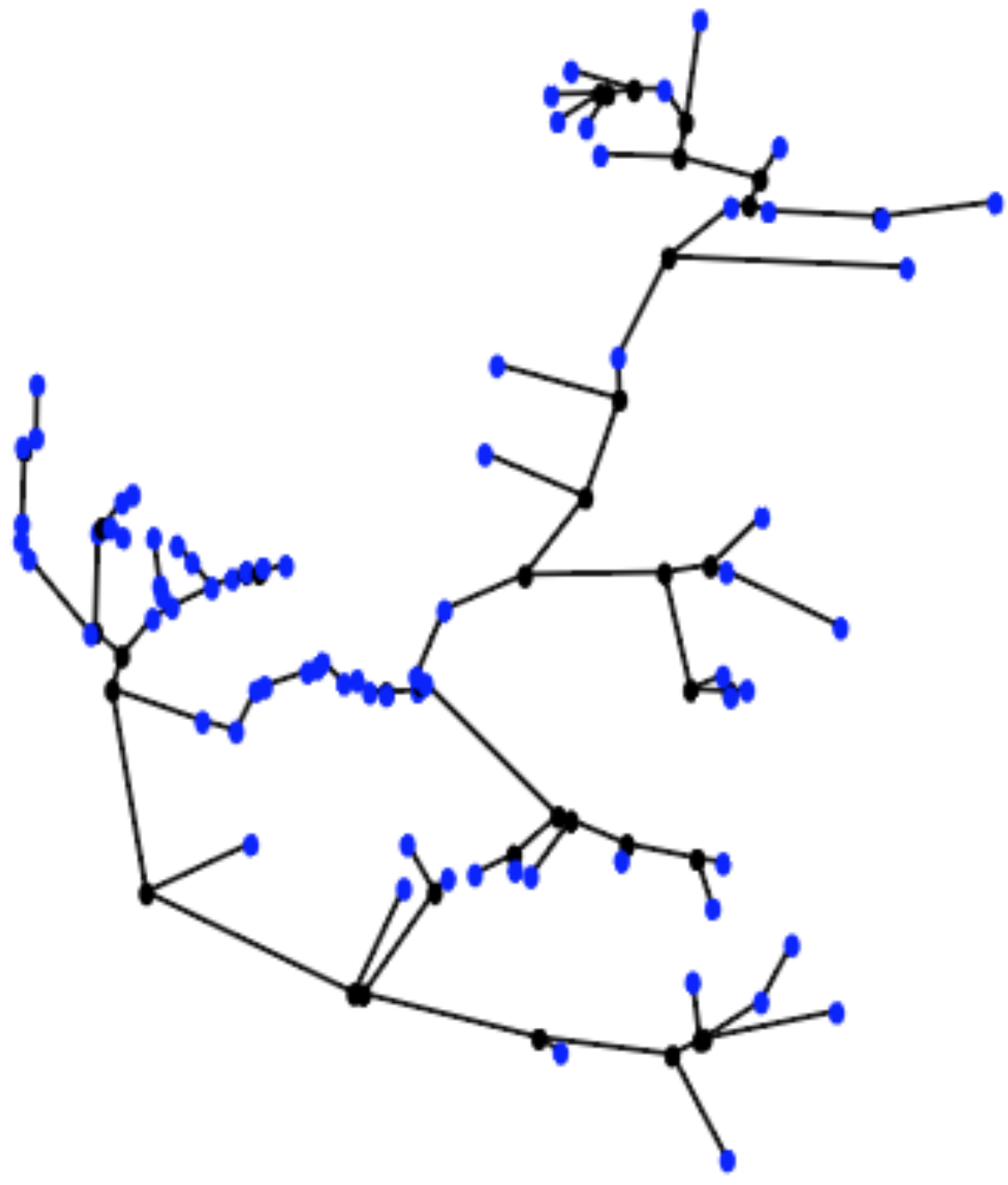


1147 Figure S3: Benchmarking results in RESISTNET showing relationships of peak memory usage and total runtime with increasing numbers of processors. All tests used a dataset of 112 network edges ( $=2,248$ individual contiguous stream segments) and $\mathrm{N}=78$ populations. The model population was composed of 50 models examining 10 randomly selected environmental variables, with the genetic algorithm proceeding for 10 generations. All runs received the same random number seed to reduce stochasticity due to model choice. Tests were performed on a 16core Linux computer with 256 gb memory.

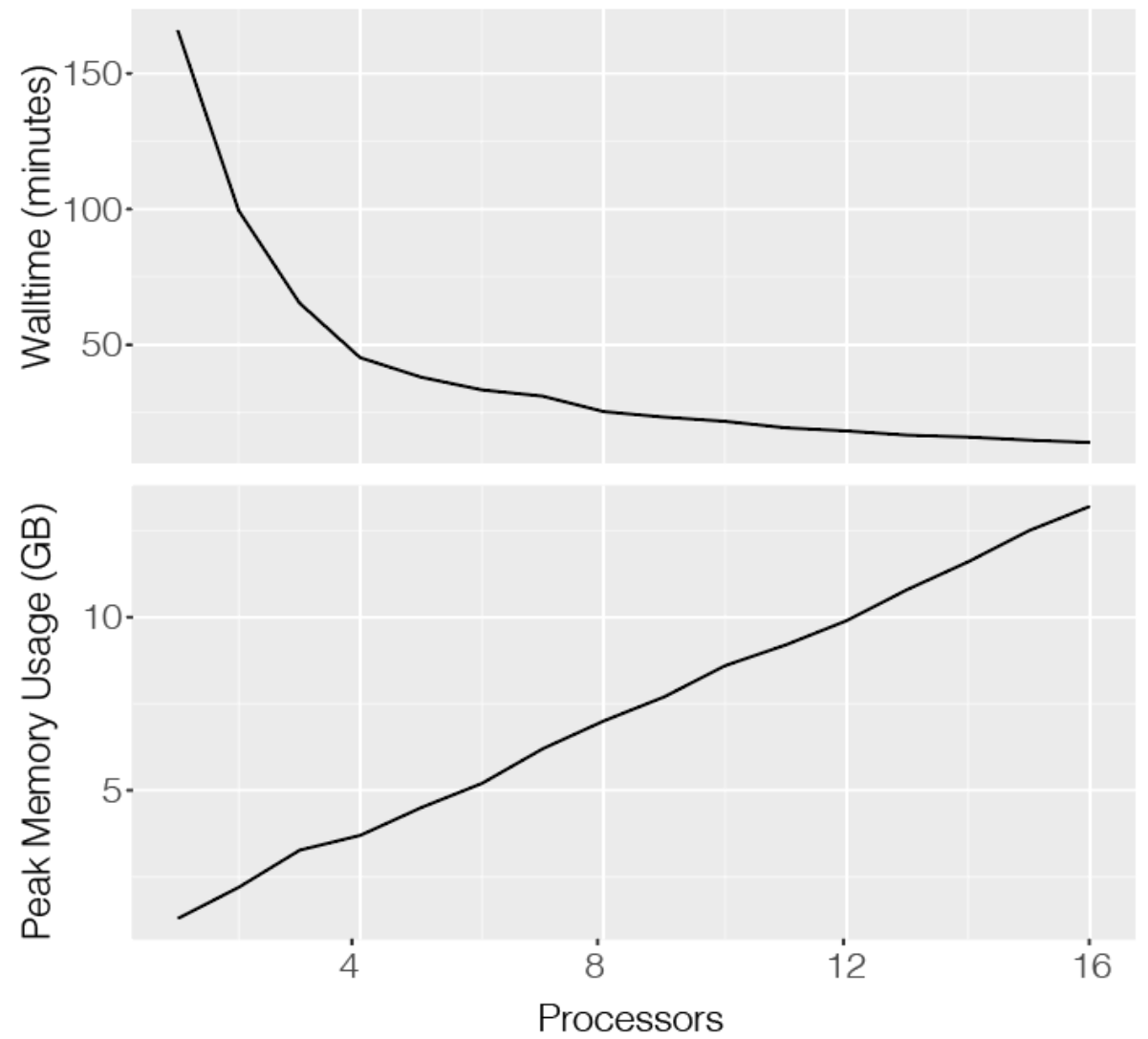


1156 Figure S4: Benchmarking results showing increase in runtime as a function of number of 1157 generations when 16 total threads are spread as: 1) 16 parallel processes in RESISTNET, with each 1158 dedicating a single process to Circuitscape ( $\mathrm{T}=16, \mathrm{C}=1)$; 2) 8 RESISTNET processes, each 1159 dedicating 2 threads to Circuitscape $(\mathrm{T}=8, \mathrm{C}=2)$; and 3) 4 RESISTNET processes, each dedicating 11604 threads to Circuitscape ( $\mathrm{T}=4, \mathrm{C}=4)$. All runs evaluated an identical model population size of 116150 , with a fixed random number seed.

1162

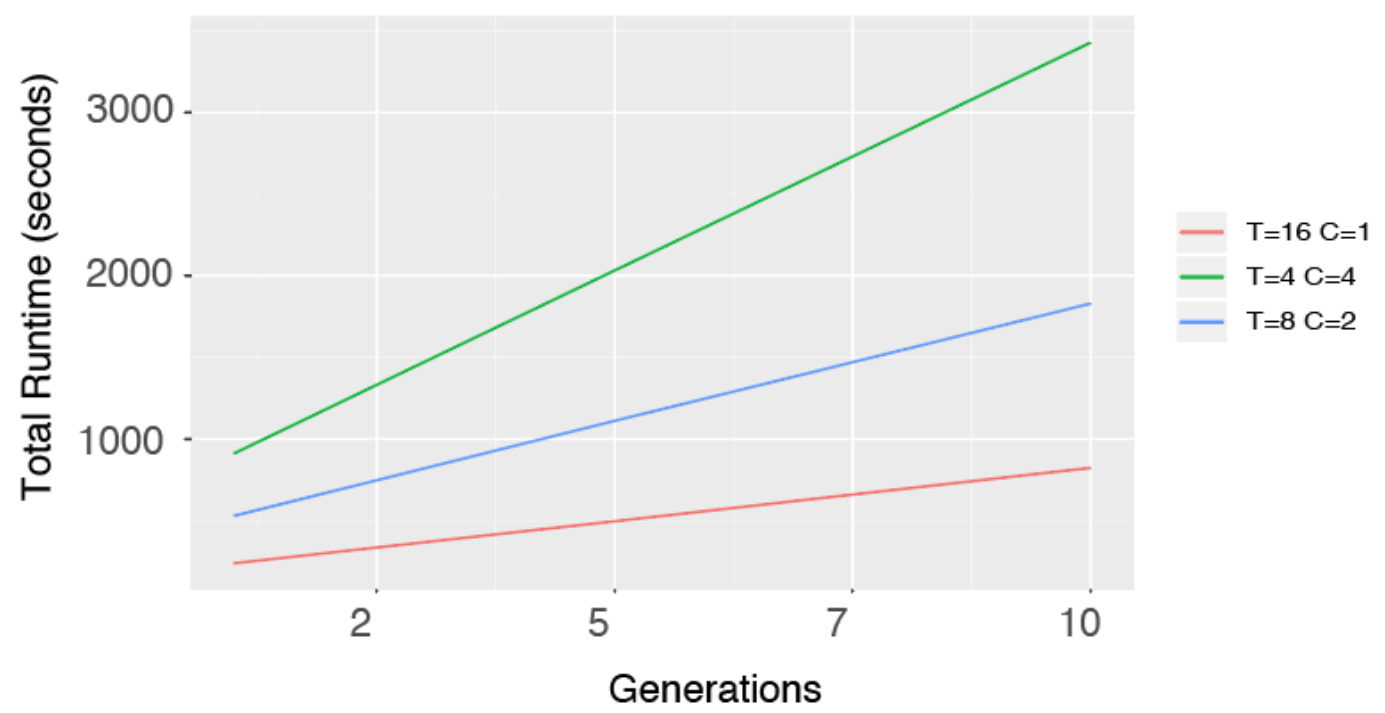


1165 Figure S5: Fitness through time for four RESISTNET replicate runs. Solid lines show the fitness 1166 (AIC value) of the 'best' model in each generation, and the shaded region shows the range for 1167 the population of models (mean $+/$ - standard deviation).

1168

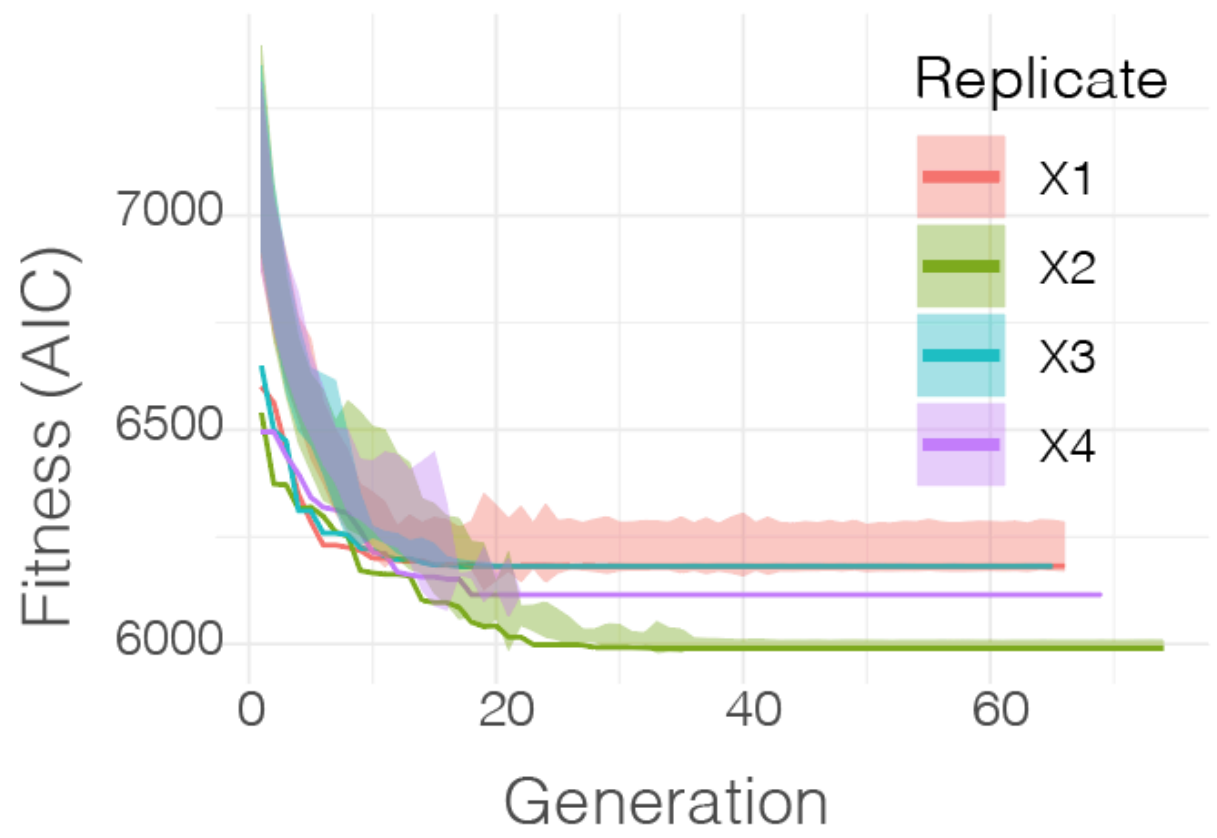


1170 Figure S6: Unrooted species-tree generated using a polymorphism-aware model (PoMo) 1171 implemented in IQ-TREE using a GTR + G nucleotide substitution model with 4 rate categories, 1172 and a virtual population size of 19 implemented in the polymorphism model.

1173

1174

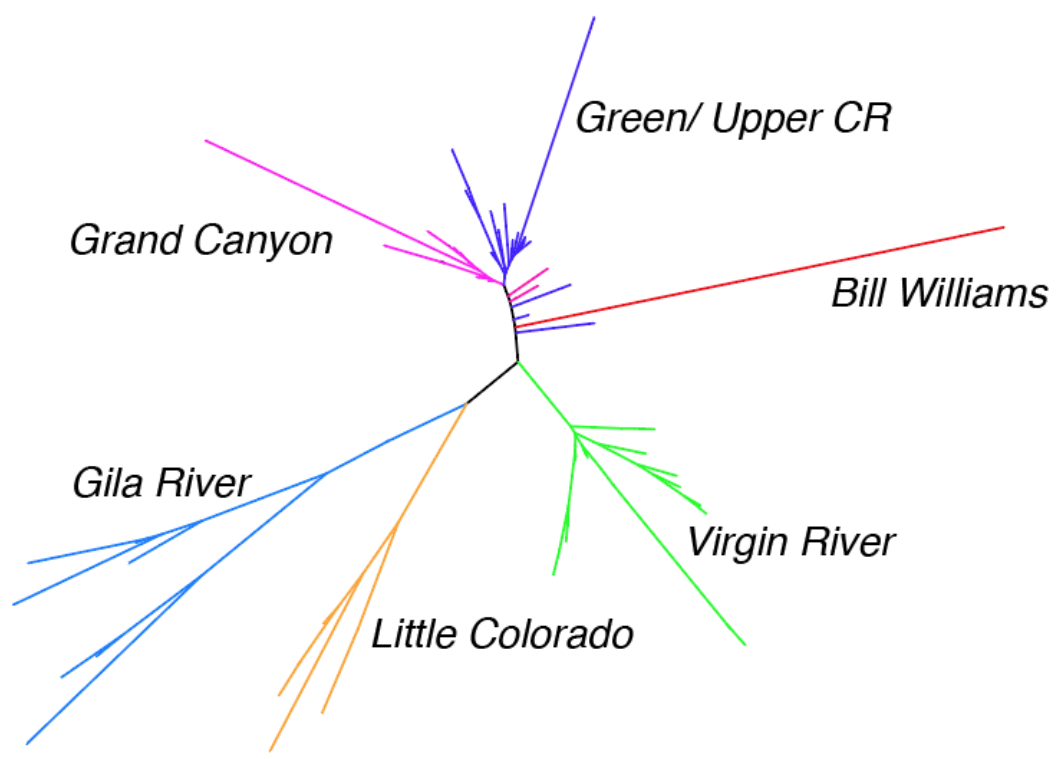

